\title{
Effect of Turbine Weight on the Seismic Response of a Wind Turbine-Monopile System Located in Liquefied Multilayer Soil
}

\author{
Mehran Tirandazian (iD) and Gholamreza Nouri (iD) \\ Faculty of Engineering, Kharazmi University, Tehran, Iran \\ Correspondence should be addressed to Gholamreza Nouri; r.nouri@khu.ac.ir
}

Received 7 November 2020; Revised 2 October 2021; Accepted 24 October 2021; Published 13 November 2021

Academic Editor: Shuang Li

Copyright (c) 2021 Mehran Tirandazian and Gholamreza Nouri. This is an open access article distributed under the Creative Commons Attribution License, which permits unrestricted use, distribution, and reproduction in any medium, provided the original work is properly cited.

\begin{abstract}
The core objectives of sustainable development are to develop access to renewable, sustainable, reliable, and cost-effective resources. Wind is an essential source of renewable energy, and monopile wind turbines are one method proposed for harnessing wind power. Offshore wind turbines can be vulnerable to earthquakes and liquefaction. This numerical study defined the effects of wind turbine weight on the seismic response of a wind turbine-monopile system located in liquefied multilayered soil with layer thicknesses of 5, 10,15, and $20 \mathrm{~m}$ using four far-field records. OpenSees PL analysis indicated that if the liquefied sand had a lower density or a thickness of more than $10 \mathrm{~m}$, then an increase in the earthquake acceleration beyond $0.4 \mathrm{~g}$ caused the pile to float like liquefied soil and to lose its vertical bearing capacity. Moreover, increasing the wind turbine power from 2 to $5 \mathrm{~kW}$ had no significant effect on the soil-structure interaction response. As the earthquake acceleration increased, the bending moment of the pile-column also increased as long as liquefaction did not occur and the pile-column deformation remained rotational-spatial in shape. As the acceleration and liquefaction increased and the pile began to float in response to its transverse motion, there was no significant difference in the pile-column displacement along the length, but there was a decrease in the pile-column bending moments. As this phenomenon increased and the pile continued to float, transformation of the pile increased the difference between the displacement of the pile-column along its length and further increased the bending moments. These results were derived from multiple correlation analysis, the bending moment relations, and lateral displacement of the pile-column of the wind turbine.
\end{abstract}

\section{Introduction}

Today, wind is an essential source of energy worldwide. Wind is a promising source of renewable energy, and wind turbines are increasingly used in offshore areas. A monopile foundation is a commonly used foundation for offshore wind applications because of its good load-bearing capability and initial cost [1]. Figure 1 shows the main countries that are developing and investing in offshore wind power as reported by the Global Wind Energy Council $[2,3]$.

Some countries, such as the USA, China, India, and those in southeast Asia, are located in seismically active regions and are also adjacent to subduction zones (blue lines in Figure 1), where there is a chance of magnitude M9-class megathrust earthquakes [2]. This indicates that the earthquake risk is relatively high for newly built offshore wind farms. For these types of structures, a reliable design and consistent modeling and assessment methods are highly recommended. Moreover, since wind farms are being widely developed in seismically active regions, the extent to which earthquake loads can increase the structural demand on offshore wind turbines requires investigation. The final outcomes, reported numerically, could be affected by the details of modeling or by the soil-structure interaction, which can have a substantial effect on the performance of such a structure $[4,5]$.

\section{Literature Review}

Many large-scale offshore wind turbines use monopile foundations as a way of saving time and money. Bisoi and Haldar [6] conducted a feasibility study of design 


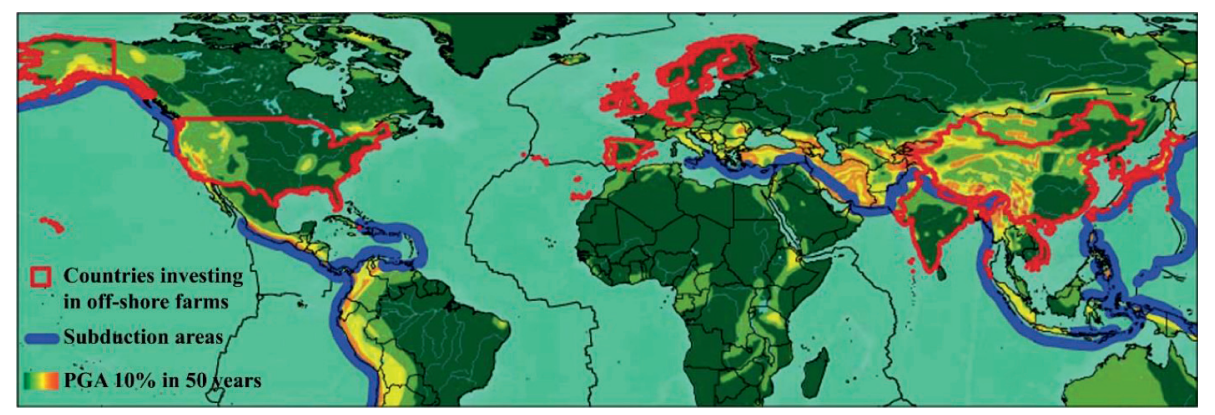

FIGURE 1: Countries investing in offshore wind farms (red boundaries), subduction trenches (blue lines), and global seismic hazard areas [2].

approaches and investigated three-bladed offshore wind turbines (OWT) with $2 \mathrm{MW}$ and $5 \mathrm{MW}$ monopile supports in clayey soil. A linear beam was used for modeling the OWT system, and the interaction between the soil and structure was evaluated by attaching American Petroleum Institutebased cyclic p-y springs to the monopile. Austin and Jerath [7] studied how the interaction of the soil, foundation, and structure affected the seismic response of $65 \mathrm{~kW}, 1 \mathrm{MW}$, and $2 \mathrm{MW}$ horizontal-axis wind turbines with steel towers featuring truncated cones. They examined the foundations with designs based on frequency (spread foundation, monopile, pile group with cap, and anchored spread foundation). They made several recommendations for simplifying the analysis of the soil-foundation-structure interactions in wind turbines subjected to seismic loading.

Kjørlaug and Kaynia [8] investigated the dynamic response of wind turbines supported on monopile foundations subjected to horizontal and vertical earthquake excitation by considering a nonhomogeneous, deep-soil stratum. Vertical earthquake excitation proved critical in seismic regions with typical low-to-moderate earthquake intensities.

Risi et al. [2] examined the structural performance of a typical offshore wind turbine subjected to strong ground motion. They developed finite-element (FE) models for offshore wind turbines and subjected them to unscaled natural seismic records. They concluded that offshore wind turbines supported by monopile foundations are remarkably susceptible to extreme crustal and plate interface earthquakes and that susceptibility increased when the supporting soil was soft.

To avoid overestimating the seismic capacity of offshore wind turbines, there is generally a need for refined structural modeling. Yeter et al. [9] investigated the effect of uncertainty arising in soil-pile interaction modeling on the predictions and dynamic structural response of the support structures which are used in offshore monopile wind turbines. They factored in a parameter so that excessive usage of steel could be avoided for the penetrating pile structure. The uncertainties were then included in probabilistic free vibration analysis, and the contribution of each random variable was estimated for the scattered responses using sensitivity analysis. The findings showed that uncertainty involved in soil profile modeling significantly affected the coefficient of variation of the natural frequency and was a key factor that should be included when evaluating the fatigue life of support structures for offshore wind turbines.
Li et al. [10] presented an innovatively designed monopile foundation of a more creative nature than that of the traditional large-diameter monopile foundation that could reach a higher capacity of axially load bearing. Piles with a 1-hole or 4-hole restriction plate added to the inside of the pile to intensify the soil plug effect were studied to examine plate-shape effects. Models with different diameters and restriction plate types were investigated. This innovatively developed pile proved to have a higher bearing capacity compared to the pipe pile. The research attempted to establish a design code for these inventive piles and offered a design reference for large-scale offshore wind turbine projects.

Arshad and O'Kelly [11] described the details of the geometric design, nominal size, and structural and environmental loading for existing and planned OWT structures supported by monopile foundations. Luo et al. [12] presented a simplified approach for the reliability-based design of laterally loaded drilled shafts with regard to the spatial variability of the soil. They used a conventional reliability method applied by variance reduction. They developed an algorithm for back-calculation that reduced the reduction factor and characteristic length for different shaft slenderness ratios. The study concluded that the simplified approach could yield responses for drilled shafts that were equivalent to those produced by more complex processes such as random field modeling. In addition, the new approach does not require knowledge of random field theory; therefore, it can be an efficient design tool for all geotechnical engineering practices.

Nimbalkar et al. [13] developed a numerical model based on the boundary element approach to investigate the performance of a monopile subjected to torsional cyclic loading. The outcomes showed that the model was able to capture degradation in the axial pile capacity caused by torsional cyclic loading with adequate accuracy and parametric examination. This finding demonstrated that the frequency, amplitude, and number of cycles all had roles in the torsional cyclic response of the pile.

Arshad and O'Kelly [14] reviewed numerous issues related to wind-power generation resources. They reported that the current global capacity of previously installed windpower generation structures could increase from the current number of 540 (2017) to $5800 \mathrm{GW}$ by the year 2050. The wind energy potential in terms of the vertical wind-speed profile signified the wind-speed distribution. The effects of 
turbulence and gusts were explored in detail by this study, which predicted an increase in global wind energy from its current level of approximately $4 \%$ of the electricity generation mix to roughly $40 \%$.

Yang et al. [15] established a simple formula for analyzing the fundamental system frequency in the preliminary design of an offshore wind turbine with a monopile foundation. Their parametric investigation showed that the tower length, tower base diameter, tower wall thickness, pile diameter, and pile length are all key parameters affecting the fundamental frequency of the offshore wind turbine system and should be comprehensively adjusted. Roach et al. [16] used a reference turbine attached to a monopile substructure. FAST (fatigue, aerodynamics, structures, and turbulence) simulation outputs from feasible ultimate and fatigue loading design load cases were analyzed and interpreted. The results revealed the importance of control-system failure safety and mitigation in electrical network loss.

Li et al. [1] proposed a hybrid monopile-friction wheelbucket (MFB) foundation for offshore wind turbines. They tested five hybrid foundations with variable dimensions in sandy soil. The findings showed that the ultimate bearing capacity of the hybrid MFB foundation was four times greater than that of a monopile foundation. Byrne et al. [17] described a new one-dimensional design model for monopile foundations formulated specifically for offshore wind turbines that are based on the conventional p-y approach. The calibrated model had results similar to those obtained from the three-dimensional (3D) finite-element calibration analysis, but at a lower computational cost.

Kementzetzidis et al. [18] promoted an advanced 3D FE modeling for the dynamic analysis of OWT-monopile-soil systems. They analyzed a state-of-the-art $8 \mathrm{MW}$ OWT model by considering the dynamic soil-monopile interaction and pore pressure effects. Page et al. [19] presented a model for the foundation response which, contrary to the API p-y curves [20], is capable of reproducing different foundation stiffness levels for unloading and reloading and foundation damping, which depends on the loading history and can be detected in the real pile behavior. Esfeh and Kaynia [21] considered advanced liquefaction modeling for analysis of the response of monopiles in offshore wind turbines. They used FLAC3D and the SANISAND constitutive model. The study focused on the nonlinear dynamic analysis for OWTs. Wang et al. [22] investigated the dynamic responses of OWTs supported on monopile foundations in clay that were subjected to wind, wave, and earthquake actions. Their results showed the necessity of considering a combination of wind, wave, and earthquake loads when designing offshore wind turbines.

The present study numerically investigated the effects of wind turbine weight on the seismic response of turbinemonopile systems located in liquefied multilayer soil. The numerical simulations of the present study are based on the FE method. Four types of liquefied sand with thicknesses of $5,10,15$, and $20 \mathrm{~m}$ under a clay layer with a thickness of $5 \mathrm{~m}$ were considered. The wind loads of four 2 and $5 \mathrm{~kW}$ far-field records were applied to evaluate the seismic response of the turbine-monopile system.

\section{Model and Ground Motion Specifications}

3.1. Soil Layer and Boundary Conditions. The general specifications of the developed model are presented in Figure 2. The model dimensions were $120 \mathrm{~m} \times 120 \mathrm{~m}$ with $30 \mathrm{~m}$ in depth. The upper layer of soil consisted of clay with a thickness of $5 \mathrm{~m}$. The middle soil layer consisted of four layers containing liquefied sand with thicknesses of 5, 10, 15, and $20 \mathrm{~m}$ that were labeled T1, T2, T3, and T4, respectively. The lower layer was composed of dense sand. Notably, the thickness of the bottom layer was not constant and changed as the thickness of the middle layer changed $(20,15,10$, or $5 \mathrm{~m})$.

The soil mesh dimensions and the boundary conditions were determined based on Liu et al. [23] such that the soil at the far-end boundaries behaved as a free field that was not influenced by the presence of the column pile. In Liu et al. (2019), the dimensions of the model were $60 \times 60 \times 30 \mathrm{~m}$. In the present study, to ensure the absorbing border condition and the assumed boundary conditions, the dimensions of the model were $120 \times 120 \times 30 \mathrm{~m}$.

The points of the soil elements at the lower end of the soil column were closed at both degrees of freedom (DoF), and the analysis was performed using the uniform excitation command. This implies that seismic wave energy was thoroughly deposited within the environment of the soil. Given the great rigidity of the chamber relative to the soil inside it, this hypothesis appears to be correct [24-26].

3.2. Column-Pile Description. The column pile in the model was designed having a diameter of $2 \mathrm{~m}$. The height of the column pile was $30 \mathrm{~m}, 20 \mathrm{~m}$ of which was buried in the ground and $10 \mathrm{~m}$ of which was above the ground. The column pile was designed for a $2 \mathrm{~kW}$ or $5 \mathrm{~kW}$ turbine with the following assumptions:

(a) The geometry was assumed to be $30 \mathrm{~m}$ (Figure 2(a))

(b) The modulus of the subsoil reaction was calculated based on three soil layers (clay-liquefied sand-dense sand) using Vesic equations (Figure 2(b))

(c) Based on these calculations, the top of the column pile had a maximum displacement of $171 \mathrm{~mm}$ (Figure 2(c))

(d) Based on the calculations, the maximum generated shear force was $1500 \mathrm{kN}$ (Figure 2(d))

(e) Based on the calculations, the maximum bending moment was $16877 \mathrm{kN}$-m, which was used to design the column pile (Figure 2(e))

(f) Figure 3 shows the curvature-moment diagram designed in OpenSees PL

3.3. Ground Motion. The four earthquake records which were used in this research model are listed in Table 1.

3.4. Behavioral Models of Materials. OpenSees PL software was used in this research. It is an object-oriented framework for applied simulation in earthquake engineering using the 


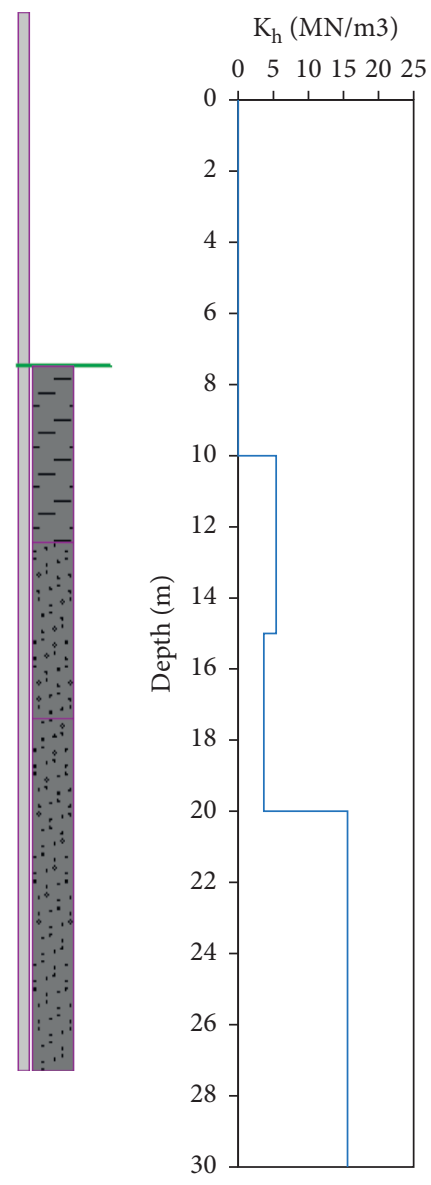

(a)

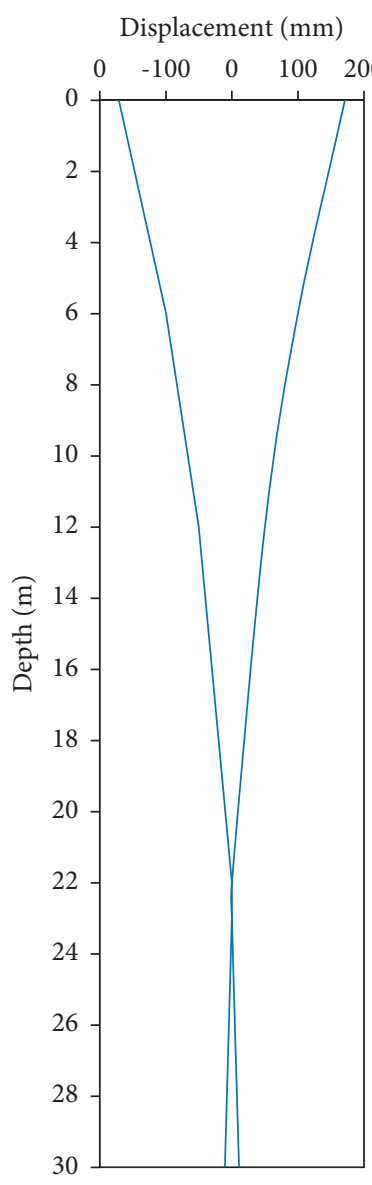

(c)

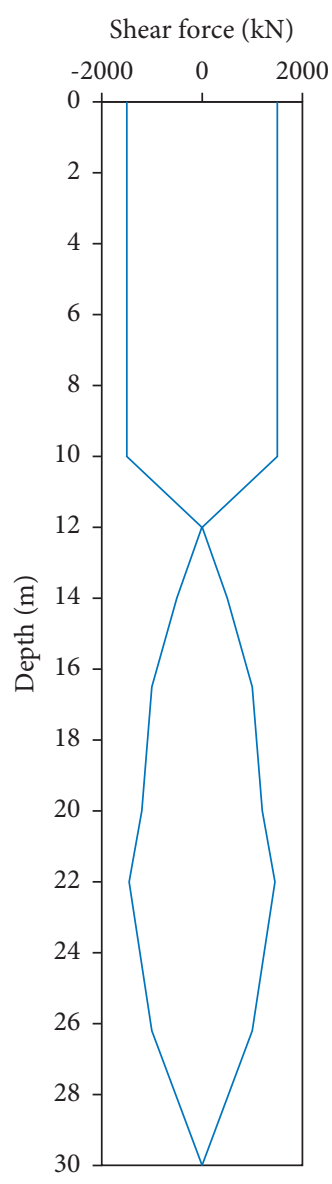

(d)

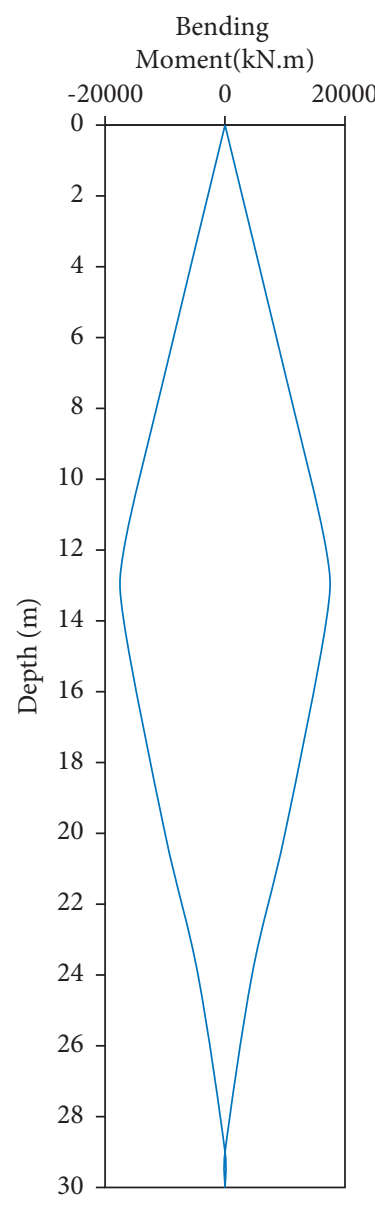

(e)

Figure 2: Column pile design: (a) geometry; (b) modulus $K_{h}$; (c) displacement; (d) shear force; (e) bending moment.

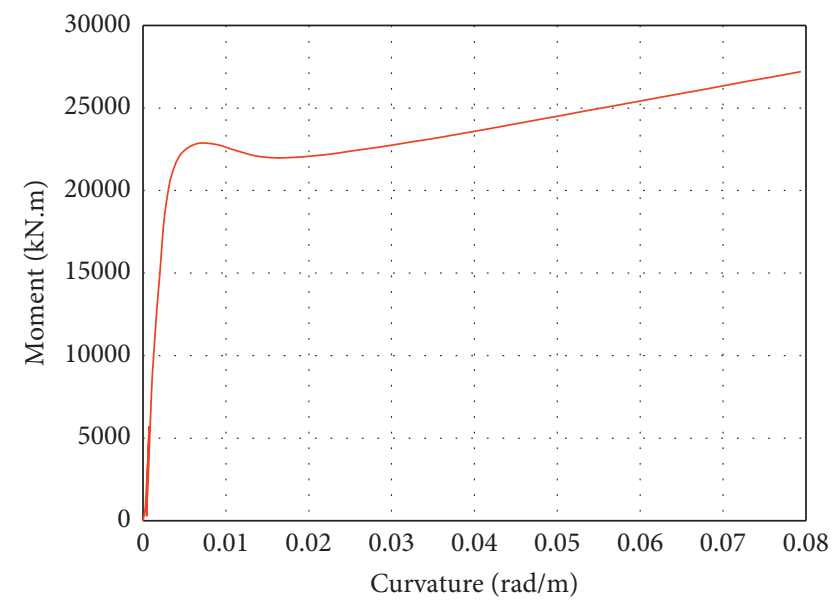

FIgURE 3: Curvature-moment diagram of column pile.

FE method. This section introduces the behavioral models of the materials used.

3.4.1. Behavioral Model for Steel and Concrete. Steel02 material was used to define steel materials in OpenSees PL.
Figure 5 shows the stress-strain curve of the material, and Table 2 shows the parameters required to define it. Concrete 02 was used to define the concrete material [28].

3.4.2. Behavioral Model of Sandy Soil. When defining a behavioral model for sandy soil, it is very important to choose sand that has the characteristics which have been proven to most often produce accurate predictions. The proposed behavioral model should be capable of modeling the main properties of saturated sand under the influence of an earthquake under the initial stress and confining stresses at an inclusive range of relative densities.

The behavioral model developed for sand in this study was based on those proposed by Prevost [29], who selected a multisurface approach for simulating the cyclic behavior of the soil. Elgamal et al. [30, 31] have improved this behavioral model to include the liquefaction effects. This behavioral model is known as the type 2 pressure-dependent multiyielding material (PDMY02) in the OpenSees PL library.

The model input parameters used for the sand materials were PDMY02, which are elastoplastic materials appropriate for simulating the properties of pressure-sensitive items under general loading conditions. Expansion or contraction 
TABLe 1: Far-field records.

\begin{tabular}{lcccc}
\hline Number & Name & Year & Station & PGA (g) \\
\hline 1 & Lytle Creek & 1970 & Cedar Springs, pumphouse 126 & 0.06 \\
2 & Coyote Lake & 1979 & SJB overpass, bent 3 g.l & 10 \\
3 & Bishop (Rnd Val) & 1984 & McGee Creek, surface & 0.057 \\
4 & Morgan Hill & 1984 & Corralitos & 0.107 \\
\hline
\end{tabular}

TABLE 2: Element parameters in steel02.

\begin{tabular}{lc}
\hline Parameter & Description \\
\hline$\$$ matTag & Material identification number \\
$\$ \mathrm{Fy}$ & Material yield stress $(0.40 \mathrm{GPa})$ \\
$\$ \mathrm{E}$ & Modulus of elasticity $(200 \mathrm{GPa})$ \\
$\$ \mathrm{~b}$ & Rehardening ratio $(0.01)$ \\
\hline
\end{tabular}

of the volume caused by cutting and liquefaction will occur in sand and silt during unidirectional or periodic loading and are the characteristics of this material. Under gravity loading, the behavior of this elastic material is linear; however, in dynamic analysis, after updating its behavior, the stress-strain response of the elastic material changed to elastoplastic behavior. Such a material behaves in a sensitive manner that allows the determination of its parameters.

In the current study, the parameters selected were used to define the parameters of the materials used for calibration by Warburton 1995. The behavioral models were calibrated for four types of sandy soil having dissimilar numbers of standard penetration test strikes $\left((\mathrm{N} 1)_{60}\right)$.

3.4.3. Behavioral Model of Clay. Multiyield pressure-independent material was used to define the clay layer material. The input parameters of the model for the clay materials were PIMY [28]. This material was used to approximate the unidirectional and cyclic response of a set of materials with shear behavior that were not sensitive to changes in confinement. Some of these materials, for example, were organic or clay soils under rapid loading (nondrained) conditions. When a gravity load was applied, the behavior of the elastic material was linear, and in the dynamic analysis, where the behavior was updated, the stress-strain response of the material was elastic-plastic. The plasticity was defined based upon the notion of multilevel or nested surfaces.

\section{Modeling and Analysis}

The pile and surrounding soil have been modeled and studied as a continuous $3 \mathrm{D}$ environment. The advantage of such a model is the ability to monitor the liquefaction mechanism and the shrinkage and dilatant properties of liquefaction-prone soil, as well as correlation of the soil-fluid phase equilibrium equations for saturated soil as a two-phase environment (solid and fluid). If a saturated soil is drained, the permeability of the soil increases, and the loading speed decreases, it can then be considered as a single-phase environment. However, if the soil permeability decreases and the loading speed increases, for example, in the case of earthquake loading, the soil should be modeled as two-phase media with both solid and fluid phases to achieve an accurate answer.

For an effective stress analysis, correlated and noncorrelated analyses should be used. In the noncorrelated analysis, the soil deformation is calculated initially and then the pore-water pressure is obtained. In the correlated method, deformation of the soil and the excess pore-water pressure should be calculated as correlated types. Studies have shown that better results can be obtained by using correlated formulations.

A mathematical theory that is consistent with the behavior of a saturated porous environment with a fluid phase was first proposed by Biot [32] who investigated the 3D consolidation of elastic saturated soil. The Biot [32] hypothesis includes linear elastic behavior and soil uniformity, regardless of water compressibility and the effect of initial stresses, as well as the use of a Darcy relation for fluid flow.

Among the continuous analytical methods, and with the development of different behavioral models, the FE method is considered suitable for the response of column piles under the lateral spreading. Despite its time-consuming analysis and the need for powerful computers, its high accuracy led to it being chosen for use in this study.

Researchers such as Zienkiewicz and Shiomi [33] and Prevost [29] have worked on the equations governing the saturated porous environment and have proposed numerical solutions using FE methods for dynamic loading and nonlinear behavior. There are generally three correlated formulations for soil modeling. The current research used the $\mathrm{u}-\mathrm{p}$ formulation, which involves soil displacement $(u)$ and soil pressure $(p)$. In this formulation, the difference in acceleration between the liquid and solid phases as well as the fluid phase compressibility has been discarded. Each node in the 3D environment has four degrees of freedom (DoF), three for displacement and one for fluid pressure.

Numerous analyses have been performed to compare the $\mathrm{u}-\mathrm{p}$ formulation with the u-p-u formulation and they confirm its good accuracy in seismic and liquefaction problems. This formulation has been used by Zienkiewicz et al. [34] and Elgamal et al. [35]. In this method, 3D soil components with 8node brick-up elements are used where the nodes have three translational DoF plus one pore-water pressure DoF. With these two types of DoF present at every contact point, the soil medium imposes uniform pressure on the pile shaft.

The analyses using 20-8-node up elements (20 nodes: translational DoF; 8 nodes: pore-water pressure DoF) showed no noteworthy change in far-field soil behavior; however, this did complicate the explanation of the loads imposed against the pile shaft, as resultant forces of the pore pressure and effective stress did not act at the same contact points $[24,36,37]$. 
TABle 3: Analysis engine options.

\begin{tabular}{lcc}
\hline Analysis options & Static analysis & Dynamic analysis \\
\hline Constraints & Plain & Plain \\
Numberer & RCM & RCM \\
Analysis system & ProfileSPD & ProfileSPD \\
Test & NormDispIncr & NormDispIncr \\
Algorithm & Krylov-Newton & KrylovNewton \\
Aggregator & Newmark $(\gamma=1.5, \beta=1)$ & Newmark $(\gamma=0.5, \beta=0.25)$ \\
Analysis & Transient & Variable transient \\
\hline
\end{tabular}

No interface element has been included in this 3D analysis. Instead, the soil elements were directly connected to the perimeter of the cylindrical space pertaining to the pile shaft. The pile space took shape through rigid links connecting the pile centerline (nonlinear beam-column elements that define the RC pile behavior model) to the perimeter of a cylinder of $2 \mathrm{~m}$ in diameter. With the soil elements being directly connected to the pile perimeter, it was possible to examine the $3 \mathrm{D}$ effects of the pile size and spatial deformation of the soil around the pile during lateral spreading. The components of the pile have been modeled as rods considering the diameter of the pile and concrete materials used in the center area of the pile and were connected to the soil components with zero-length elements.

4.1. Problem-Solving Approach. Large numerical damping values and long time intervals were used when applying a dead load to the soil and structure. Using a large numerical damping value, the nonlinear transition analysis was able to simulate quasistatic loading conditions [38, 39]. Therefore, during the application of the dead load on the soil and structure, the analysis was severely damped when values of 1.5 and 1 were assigned to the Newmark time integration parameters ( $\beta$ and $\gamma$, respectively).

Dynamic analysis was performed using transition analysis with a variable time interval and Newmark integrator (average acceleration method). This inevitably shortened the time step if there was no convergence of the solution. In both the gravity loading and dynamic loading, transitional analysis was used to avoid problems with the numerical solution during the simultaneous use of static and transitional analysis in the modeling of the pile-soil-structure system. Table 3 summarizes the analysis options used in this study.

4.2. Analysis Procedure. In the definition of the nonlinear beam-column elements, several fiber elements were assigned to the pile. To simulate subsurface conditions, a gravitational elastic analysis was applied.

Next, transitional analysis was carried out, although it required long temporal intervals to determine the correct water pressure states of the hydrostatic cavities. The state of the soil material was updated nonlinearly and several transitional dynamic analyses were applied to accommodate the initial values. To facilitate the convergence process, these steps were completed at shorter intervals.
The points of the pile elements were connected from the deformed soil so that the structural system did not participate in the analysis of the gravitational load of the meshed soil and displacement because soil subsidence had not been applied unrealistically to the soil and structure. Several stages of transitional analysis were conducted to apply the dead load of the structure.

At this point, the liquefied soil properties were updated. From this point on, throughout the analysis over time, the behavior of these materials largely depended on the effective environmental stresses and pore-water pressures. In the last stage, time-history analysis was employed during the seismic analysis of the FE model of the pile-soil-structure system.

4.3. Model Verification. Due to the complexity of the 3D numerical modeling of a soil system and pile group, the numerical results were compared with the laboratory work of Wilson et al. [40] to ensure modeling accuracy. The laboratory data of Wilson [39] and Wilson et al. [40] relate to five physical models of centrifuges, each of which was subjected to 17 accelerometers. In the current study, only the CSP2 model (Figure 6), having a maximum acceleration of $0.41 \mathrm{~g}$, was used to validate the numerical model (Figure 7).

The CSP2 laboratory model consisted of two layers of Nevada sand. The first layer had a density of $35 \%$ and a height of $9.1 \mathrm{~m}$. The second layer had a density of $80 \%$ and a height of $11.4 \mathrm{~m}$ (realistic scale). All dimensions and mechanical parameters of the soil and piles, such as the length, area, moment of inertia, Young's modulus, and shear modulus, were considered, and the results have been provided at a realistic scale.

In the laboratory model, the pile was considered to be an empty tube made of aluminum with a density of $290 \mathrm{ton} / \mathrm{m}^{3}$ and Young's modulus of $70 \mathrm{GPa}$ with an outer diameter of $0.67 \mathrm{~m}$ and a wall thickness of $19 \mathrm{~mm}$. The lower $16.8 \mathrm{~m}$ of the pile was buried in the soil, and a load of $480 \mathrm{kN}$ was applied to the head of the pile, which was located at a height of $3.8 \mathrm{~m}$ above the ground, as an overburden. It should be noted that only half of the model was considered for numerical simulation due to the symmetry of the laboratory model.

Using the diagrams provided for the numerical and laboratory models, it was determined that the liquefaction mechanism, pore water, acceleration, and displacement values were compatible between the numerical and laboratory models. This indicated that the numerical and behavioral models selected for sandy soil would be able to simulate the behavior of the liquefied soil with appropriate 
TABLE 4: Maximum acceleration and pore pressure from FE analysis and experiments.

\begin{tabular}{lcccc}
\hline Parameter & Depth $(\mathrm{m})$ & Experimental results & FE analysis results & Difference between FE analysis and experiment \\
\hline \multirow{2}{*}{ Maximum acceleration } & $1.4 \sim 1.5$ & $0.42 \mathrm{~g}$ & $0.38 \mathrm{~g}$ & -9.5 \\
Lateral displacement $(\mathrm{cm})$ & $5.5 \sim 5.6$ & $0.28 \mathrm{~g}$ & $0.32 \mathrm{~g}$ & +14.3 \\
\hline
\end{tabular}

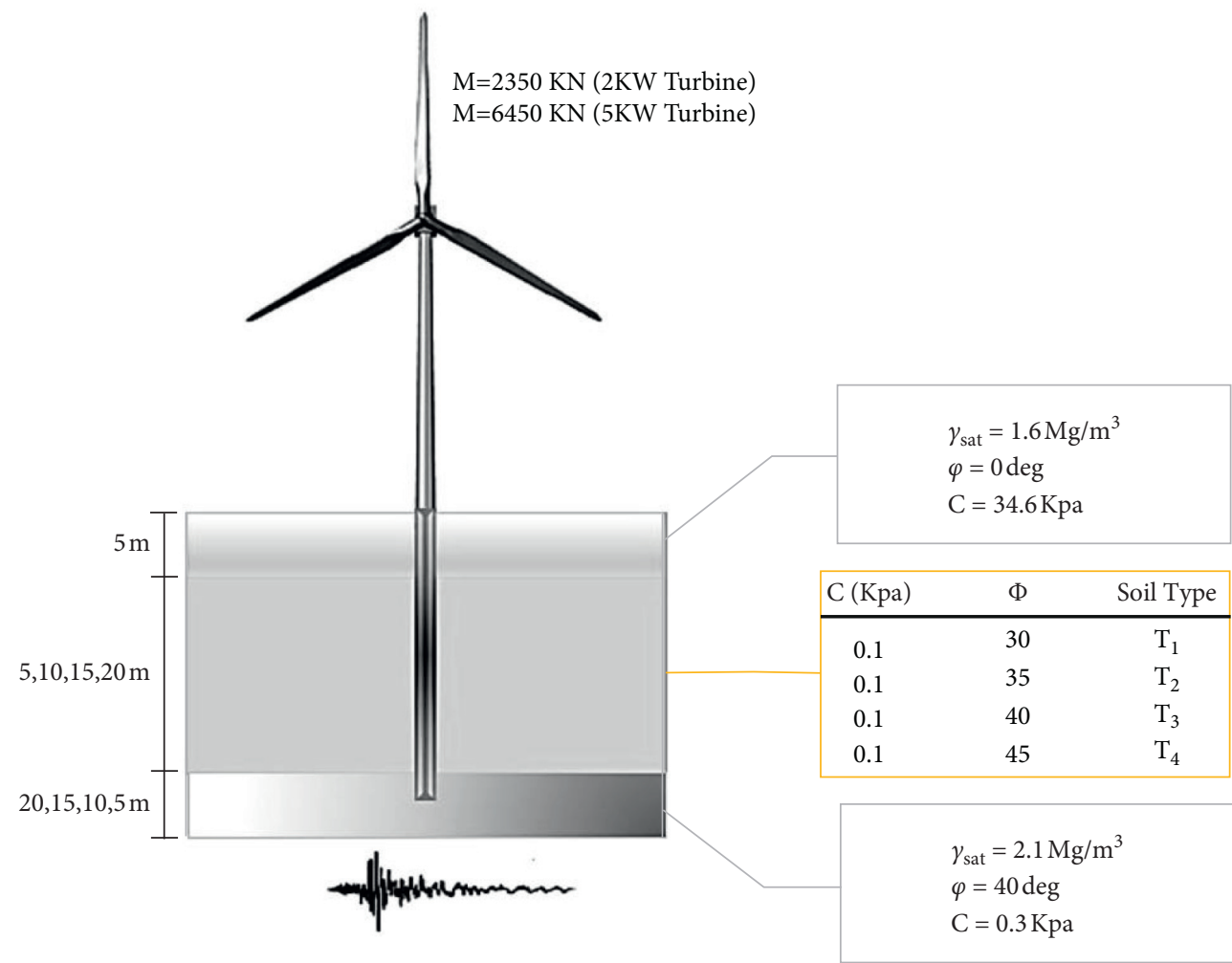

Figure 4: General specifications of model ( $\gamma_{\text {sat }}=$ saturated unit weight, $\varphi=$ friction angle, and $C=$ cohesion).

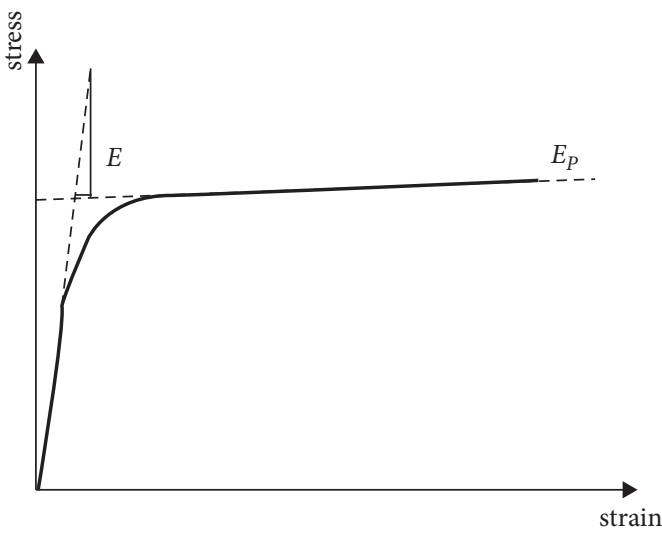

(a)

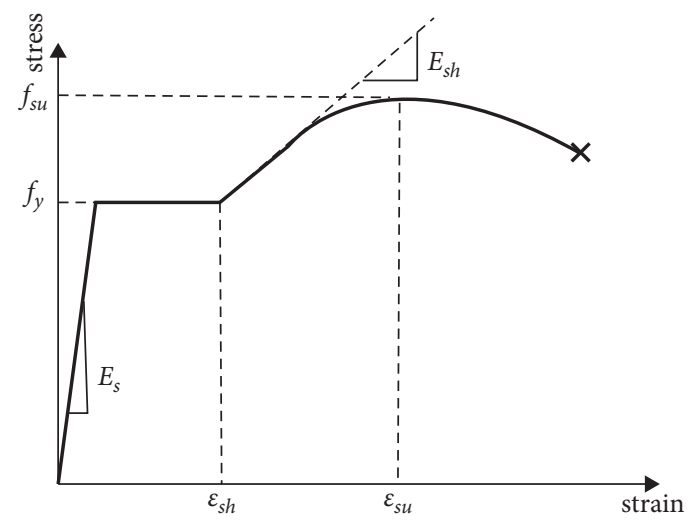

(b)

FIGURE 5: Stress-strain diagram of Steel02 elements [27].

accuracy. As the same behavioral model was used for liquefied soil, the results were sufficiently accurate in the main models.
Comparison of the graphs shows that the results of the FE model analysis were consistent with the experimental results; therefore, the FE model created was considered 


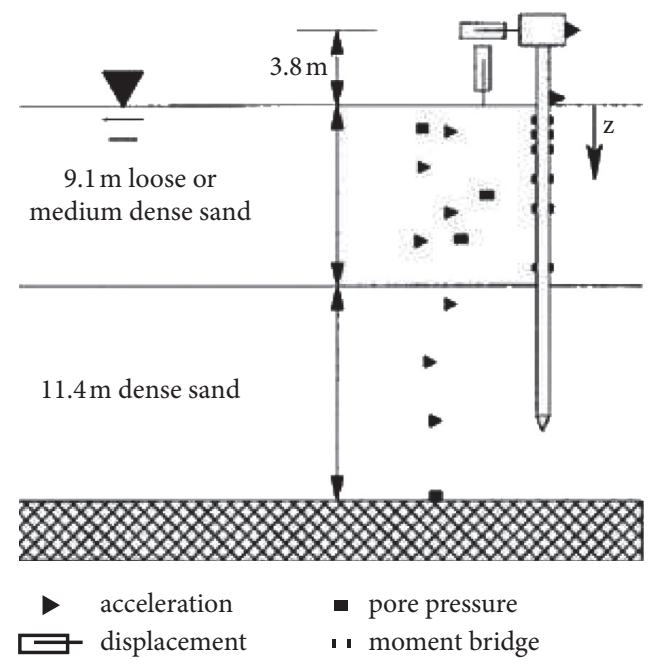

FIgURE 6: Laboratory model (CSP2) for calibrating range component model in OpenSees PL.
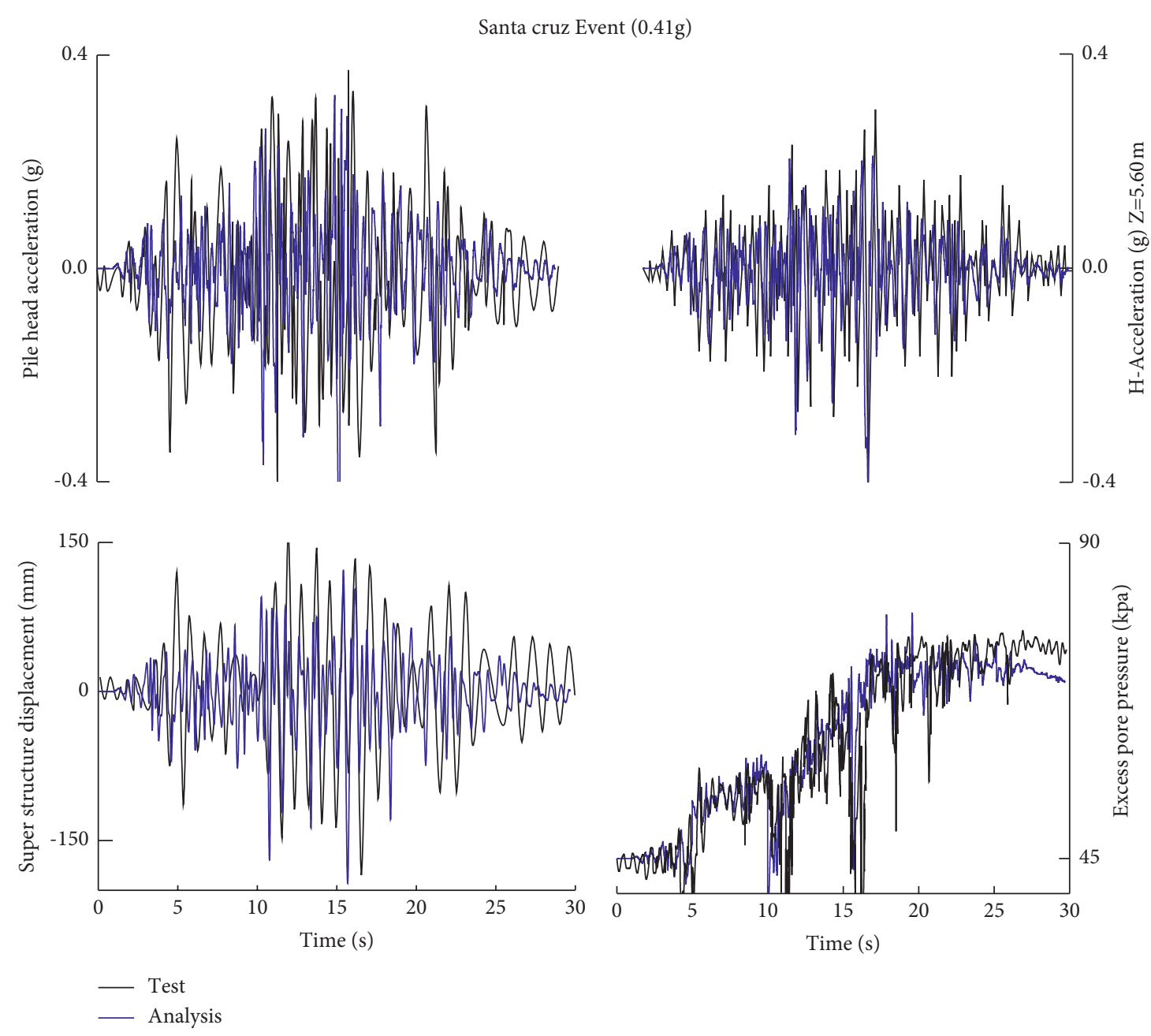

Figure 7: Acceleration diagrams based on test results and FE analysis. 


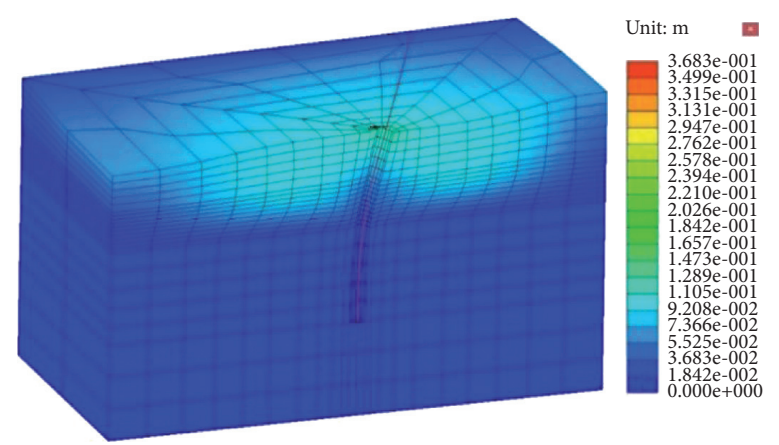

FIGURE 8: 3D diagram of lateral displacement of pile-column in liquefied soil type T1 with a thickness of $5 \mathrm{~m}$ under earthquake record 4.

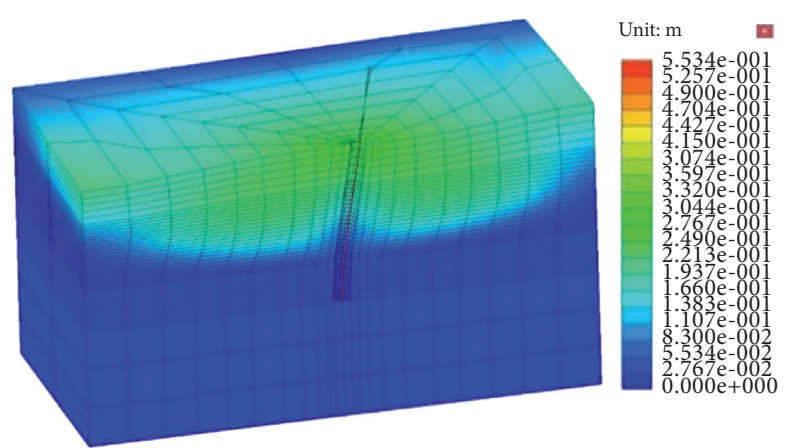

FIGURE 9: 3D diagram of lateral displacement of pile-column in liquefied soil type T1 with a thickness of $10 \mathrm{~m}$ under earthquake record 4.

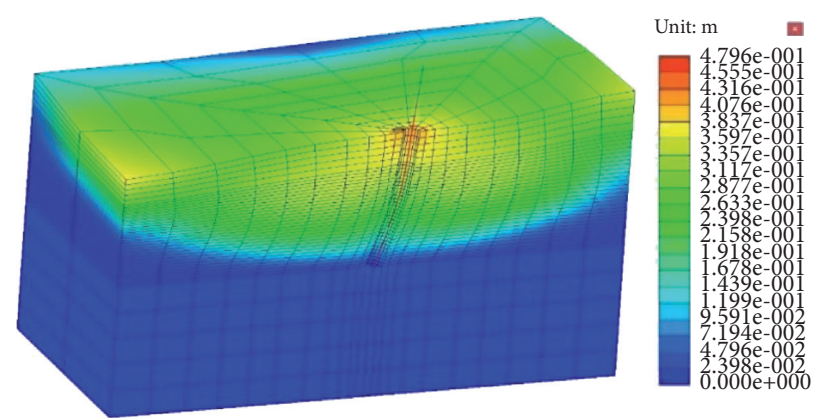

FIGURE 10: 3D diagram of lateral displacement of pile-column in liquefied soil type T1 with a thickness of $15 \mathrm{~m}$ under earthquake record 4.

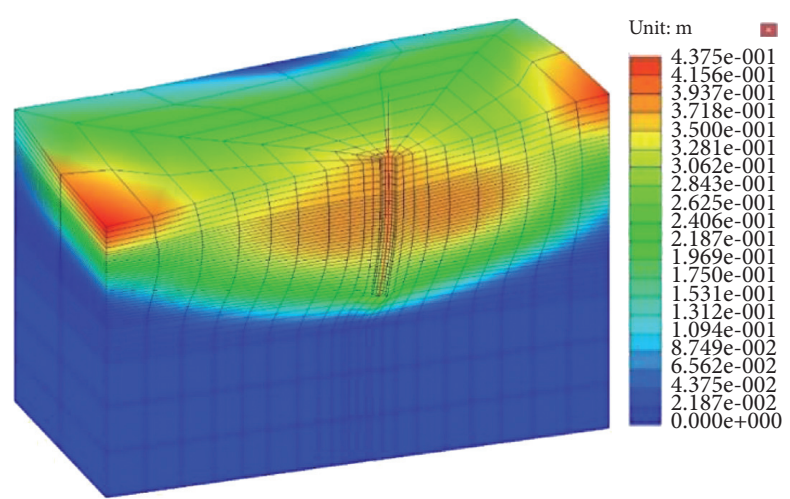

FIGURE 11: 3D diagram of lateral displacement of pile-column in liquefied soil type T1 with a thickness of $20 \mathrm{~m}$ under earthquake record 4. 

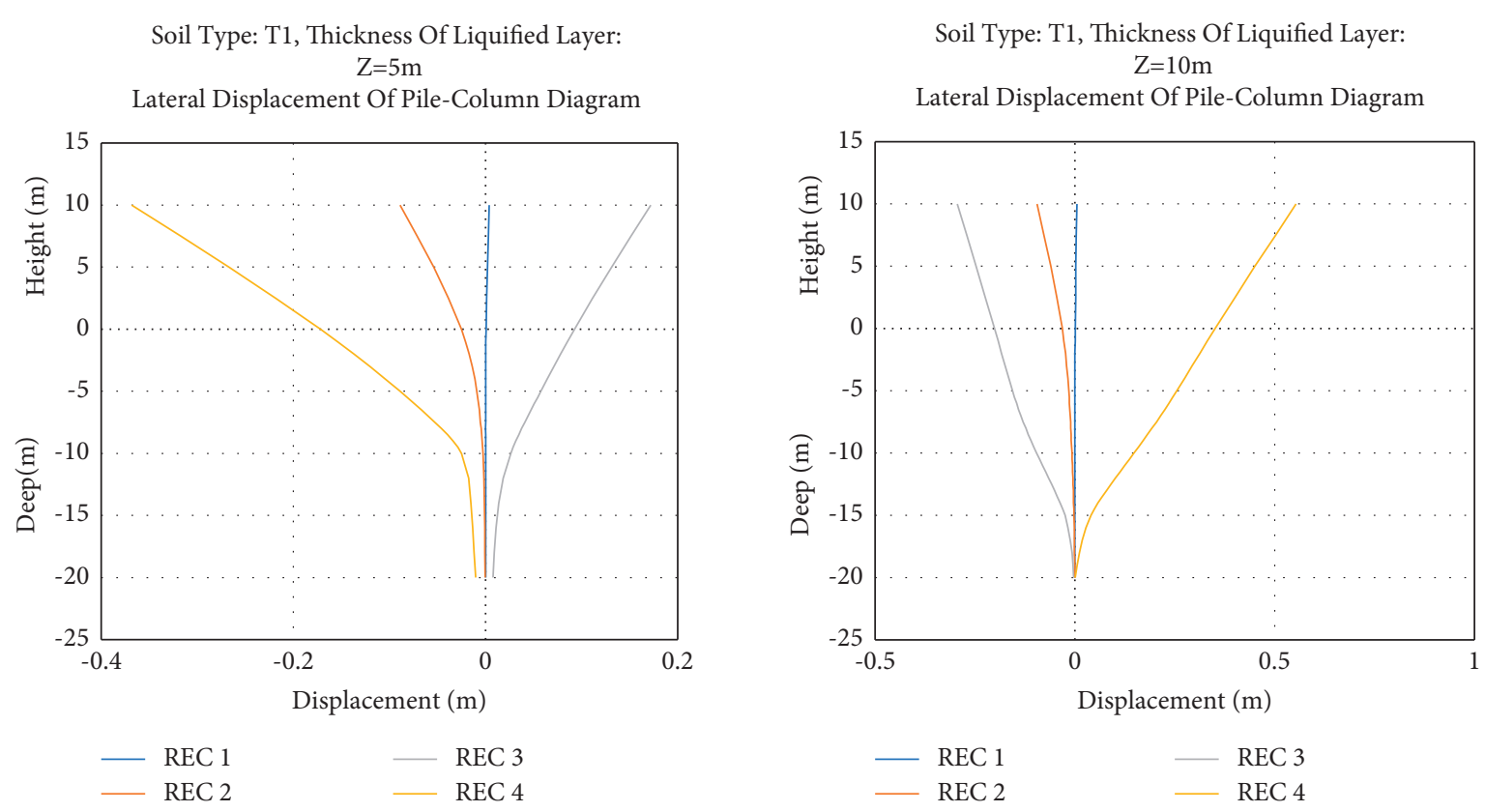

Soil Type: T1, Thickness Of Liquified Layer:
Z=15m
Lateral Displacement Of Pile-Column Diagram
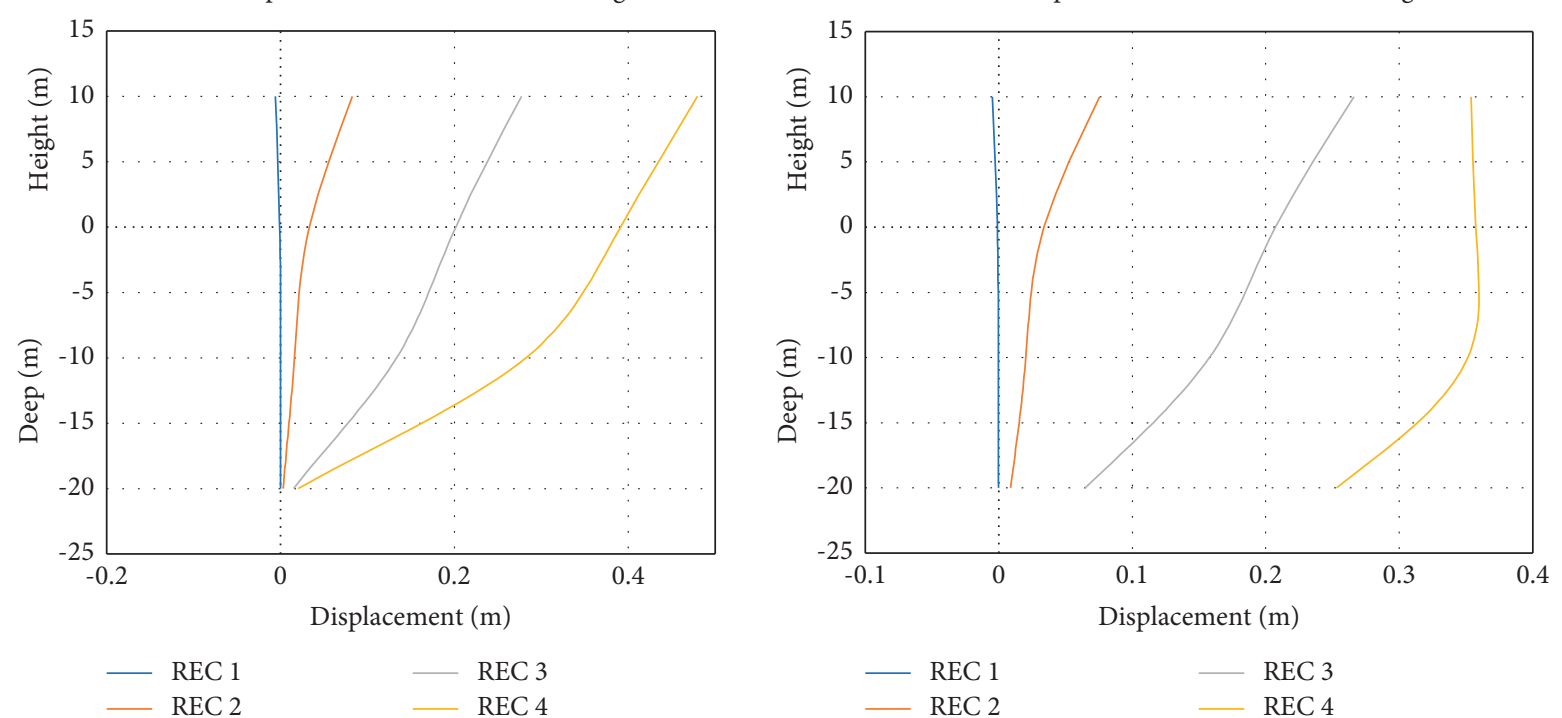

FIGURE 12: Lateral displacement of pile-column in soil type T1 with different liquefaction-layer thicknesses and earthquake records.

reliable. Table 4 allows comparison of the maximum values of the parameters.

\section{Results and Discussion}

The 3D model created in OpenSees PL was used to evaluate sandy soil prone to liquefaction by changing the following parameters:

(a) The wind turbine power at $2 \mathrm{~kW}$ and $5 \mathrm{~kW}$ (b) Four types of sandy soil with different mechanical characteristics

(c) The thickness of the liquefied layer as 5, 10, 15, and $20 \mathrm{~m}$

(d) The records of the distant-field earthquakes (four records)

Using these parameters, 128 models were created by changing each parameter and then analyzing them in 

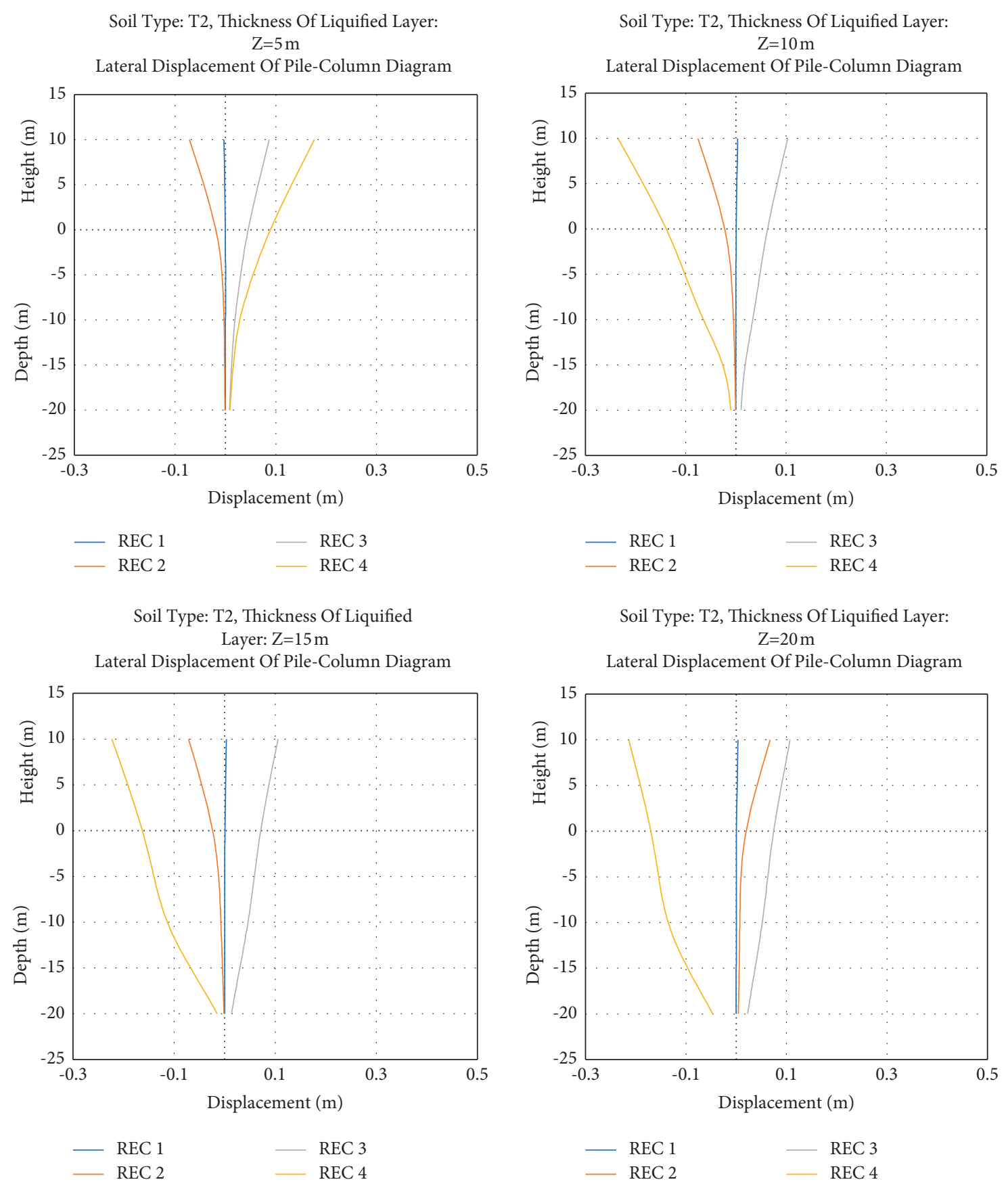

FIGURE 13: Lateral displacement of pile-column in type T2 soil with different liquefaction-layer thicknesses and earthquake records.

OpenSees PL. A total of 13 parameters were studied. The five parameters of the flexural moment, shear force, lateral displacement, rotation, and acceleration were related to the pile structure. The eight parameters of lateral displacement, acceleration, pore pressure ratio, pore pressure, shear stress, vertical stress, shear strain, and vertical strain related to the soil around the pile.
5.1. Changes in Lateral Displacement of Pile-Columns. The pile-column displacement diagrams are based on the analysis of the 128 models. Figures 8-11 show the 3D diagrams of the lateral displacement of the pile-column in liquefied soil type 1 with different thicknesses for the liquefied layer under earthquake record 4. Using the set of diagrams given in Figures $12-15$, the following results have been derived: 

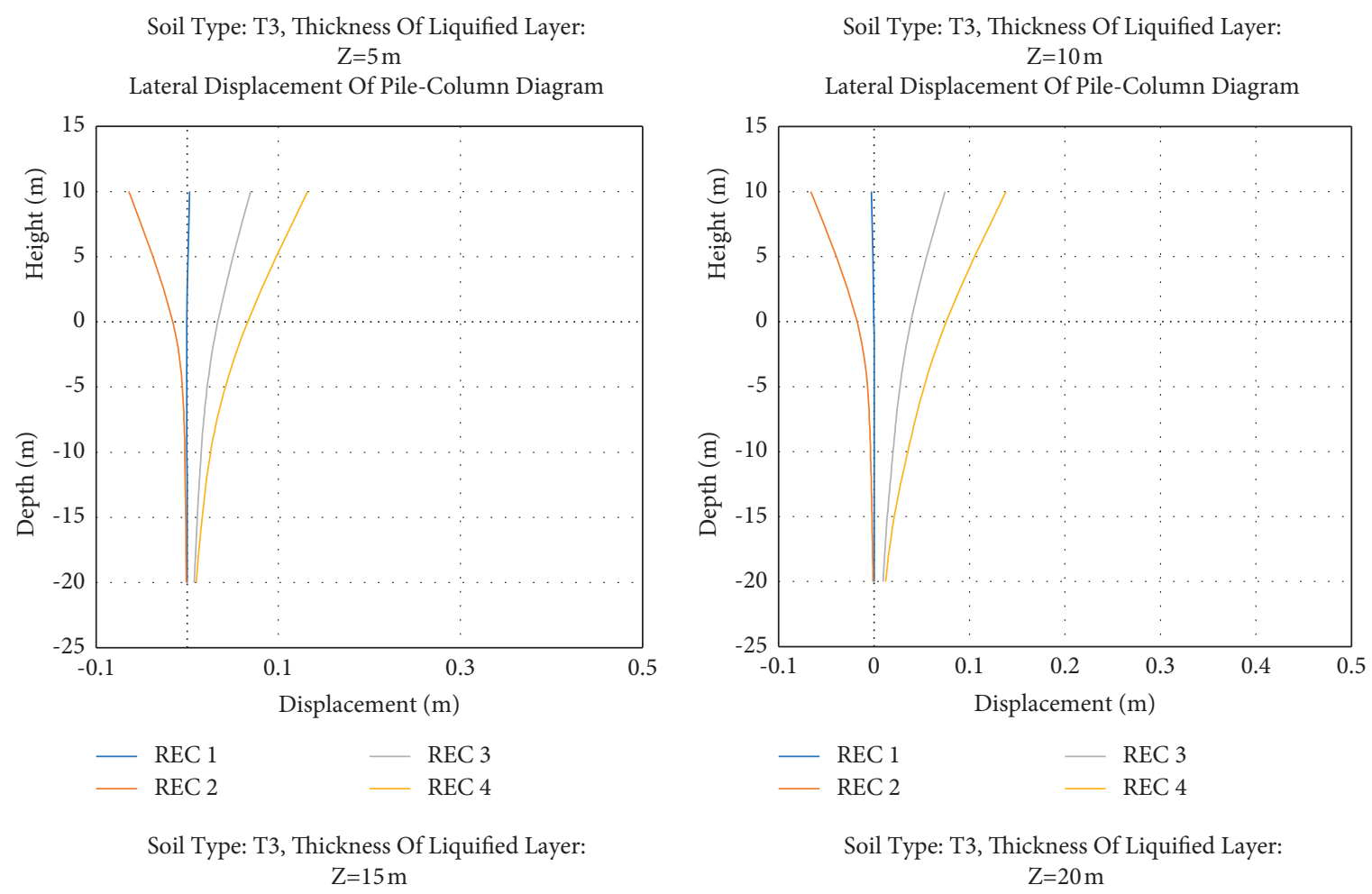

Lateral Displacement Of Pile-Column Diagram
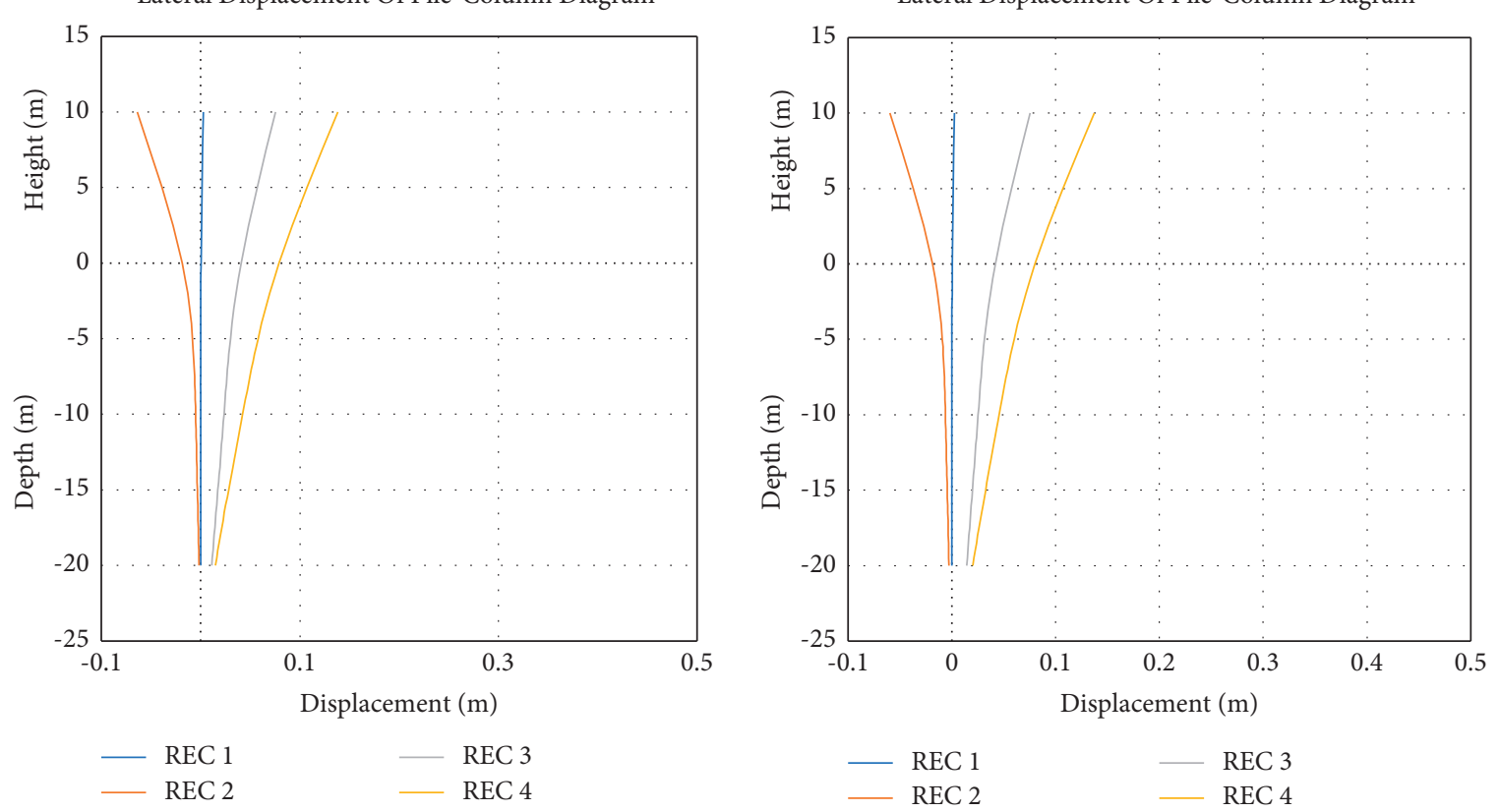

FIGURE 14: Lateral displacement of pile-column in type T3 soil with liquefaction-layer thicknesses and earthquake records.

(a) As the acceleration of the earthquake increased, liquefaction occurred and the lateral displacement of the pile-column increased.

(b) For T1 and T2 soils, as the intensity of the earthquake and the thickness of the liquefied layer increased, displacement at the end of the pile increased accordingly.

(c) For T3 and T4 soils, an increase in the thickness of the liquefied layer did not affect displacement at the end of the pile. 

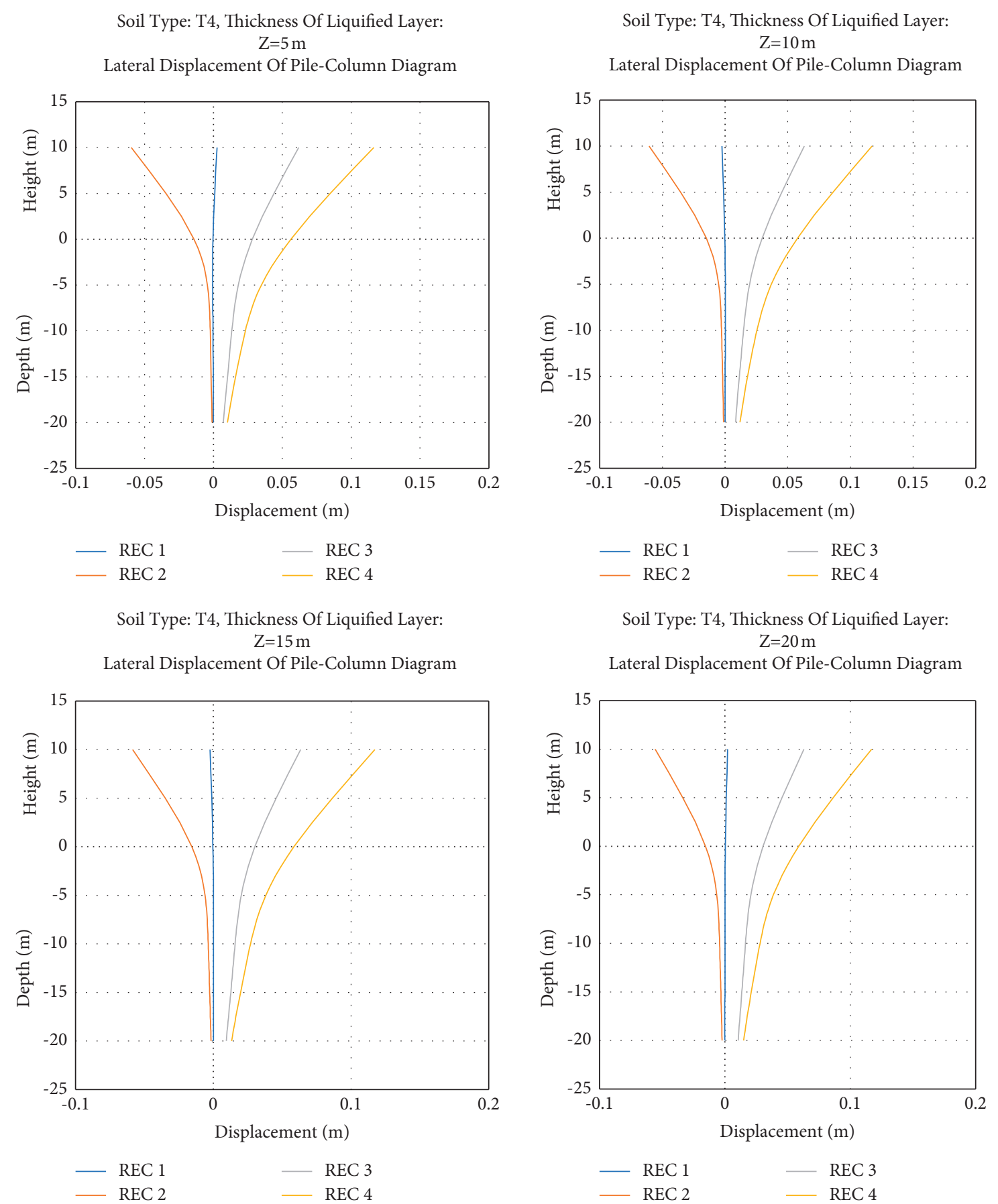

Figure 15: Lateral displacement of pile-column in type T4 soil with different liquefaction layer thicknesses and earthquake records.

(d) Given the explanation in (a), as the earthquake acceleration and depth of the liquefying layer increased, the shape or mode of lateral displacement changed from rotation displacement to tilting and then floating in soil.

(e) Given the explanation in (c), an increase in earthquake acceleration and the depth of the liquefying layer, a change in the mode or shape of displacement caused the change in the top of the pile-column to decrease. The highest lateral displacement of the top of the pile-column in T1- type soil in the liquefied layer with a thickness of $10 \mathrm{~m}$ for the $\mathrm{R} 4$ earthquake record was about $57.5 \mathrm{~cm}$. The lowest lateral displacement of the top of the pile-column in the same soil and the same earthquake record was about $35 \mathrm{~cm}$. This decrease occurred due to the buoyancy of the monopile and its transfer motion.

5.2. Changes in Bending Moment of Pile-Columns. The pilecolumn flexural moment diagrams were based on the 

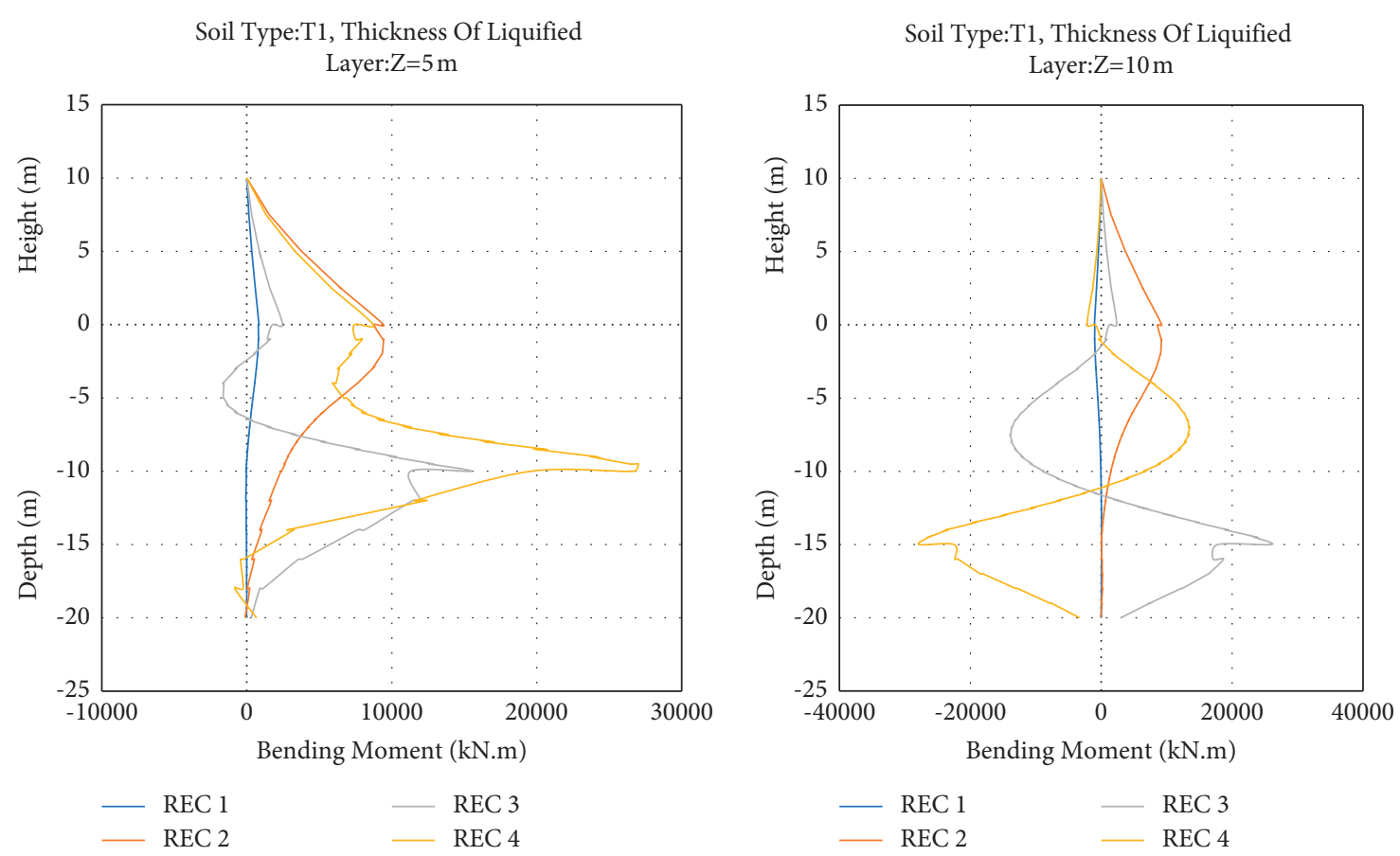

Soil Type:T1, Thickness Of Liquified Layer: $\mathrm{Z}=15 \mathrm{~m}$
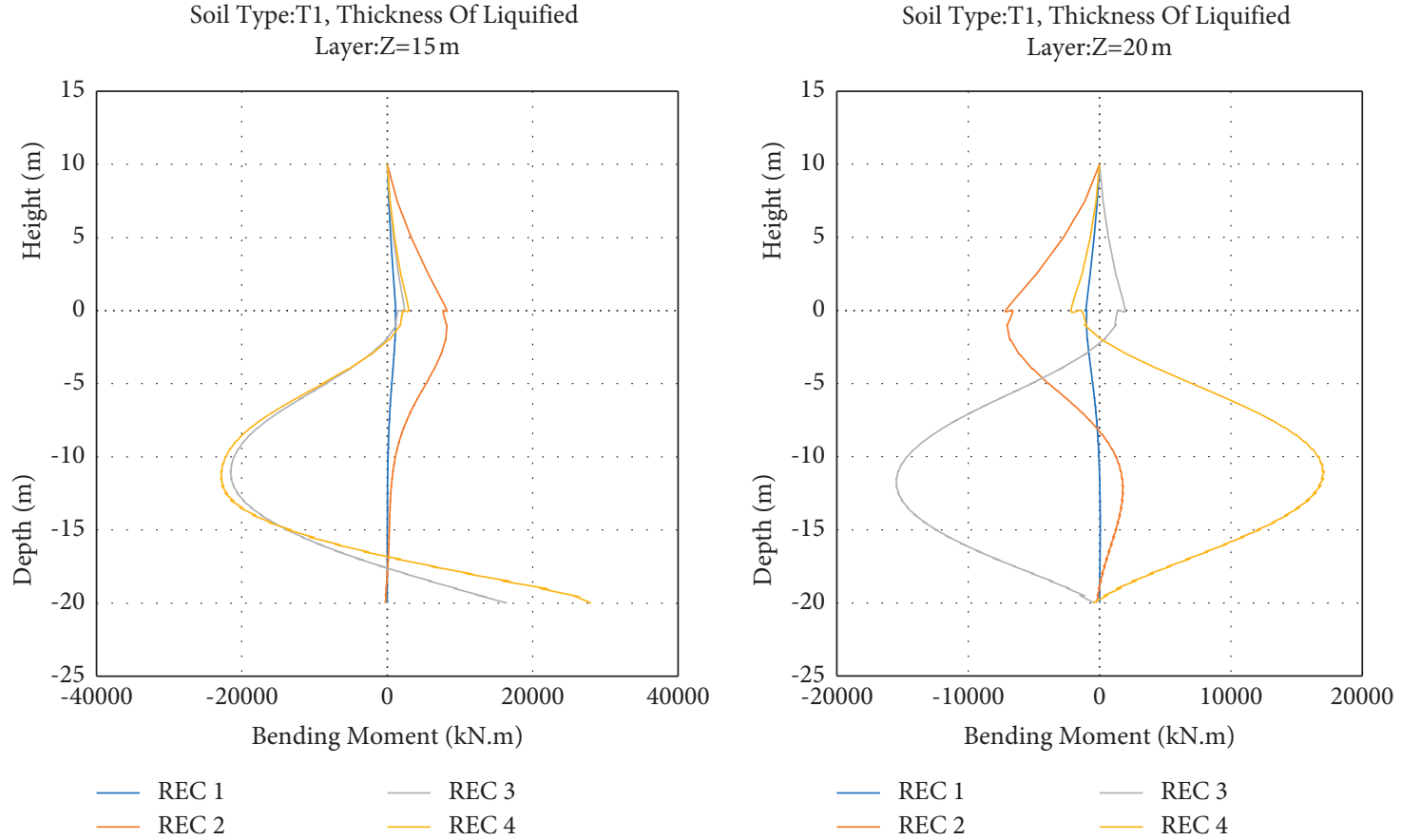

FIGURE 16: Pile-column bending moment in type T1 soil with different liquefaction layer thicknesses and earthquake records.

analysis of 128 models. The diagrams presented in Figures 16-19 were used to derive the following results:

(a) The maximum bending moment changed from near the ground surface to the end of the liquefying layer.

(b) If the shape or mode of the pile-column deformation was the rotation-displacement in soil with less density, as the seismic acceleration increased, due to both liquefaction and the increase in the pile-column length, the amount of flexural moment also increased. The highest flexural bending occurred in T1-type soil with a $5 \mathrm{~m}$ thick liquefying layer at the end of the liquefying layer $(\mathrm{Df}=10 \mathrm{~m})$ with a value of approximately $27500 \mathrm{kNm}$ for the $\mathrm{R} 4$ earthquake record.

(c) As the soil density increased in the absence of liquefaction in earthquakes with an acceleration of less than $0.4 \mathrm{~g}$, the lateral displacement of the pile-column greatly decreased and a large reduction in the flexural moment occurred. Accordingly, the 

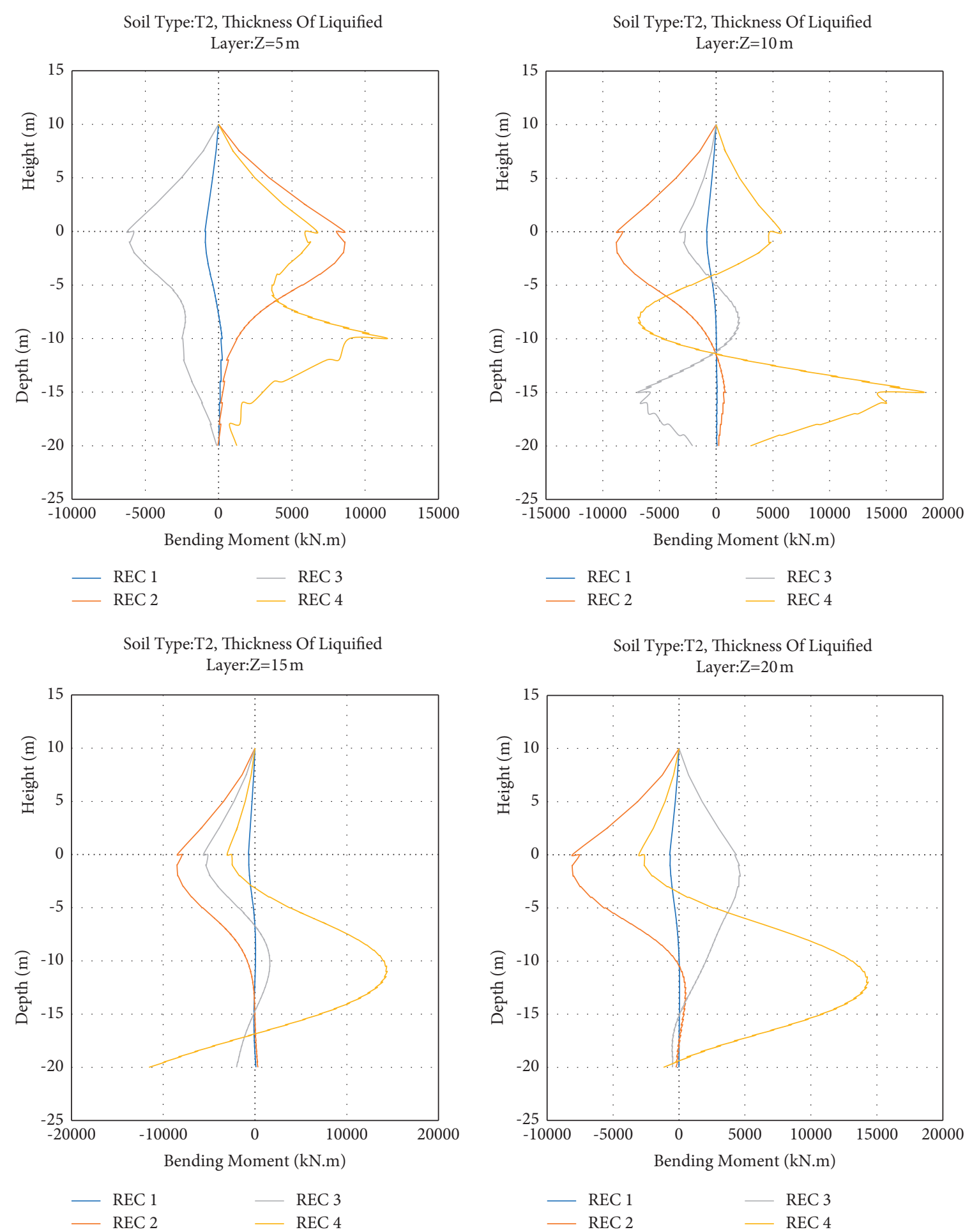

Figure 17: Pile-column flexural moment in type T2 soil with different liquefaction layer thicknesses and earthquake records.

maximum flexural moment in the pile-column in T4-type soil reached about $8000 \mathrm{kN} \mathrm{m}(71 \%$ decrease compared to the flexural moment mentioned in (b)).

5.3. Effect of Turbine Weight on Lateral Displacement. All 128 models were analyzed in OpenSees PL to examine the changes in the lateral displacement of the pile tip. The maximum values of displacement of the pile tip were obtained and its envelope curve was drawn. Figure 20 shows the envelope for displacement diagrams of the $2 \mathrm{~kW}$ turbine head displacement, and Figure 21 shows the envelope diagrams for the $5 \mathrm{~kW}$ turbine. Examination of the figures provided the following results: 

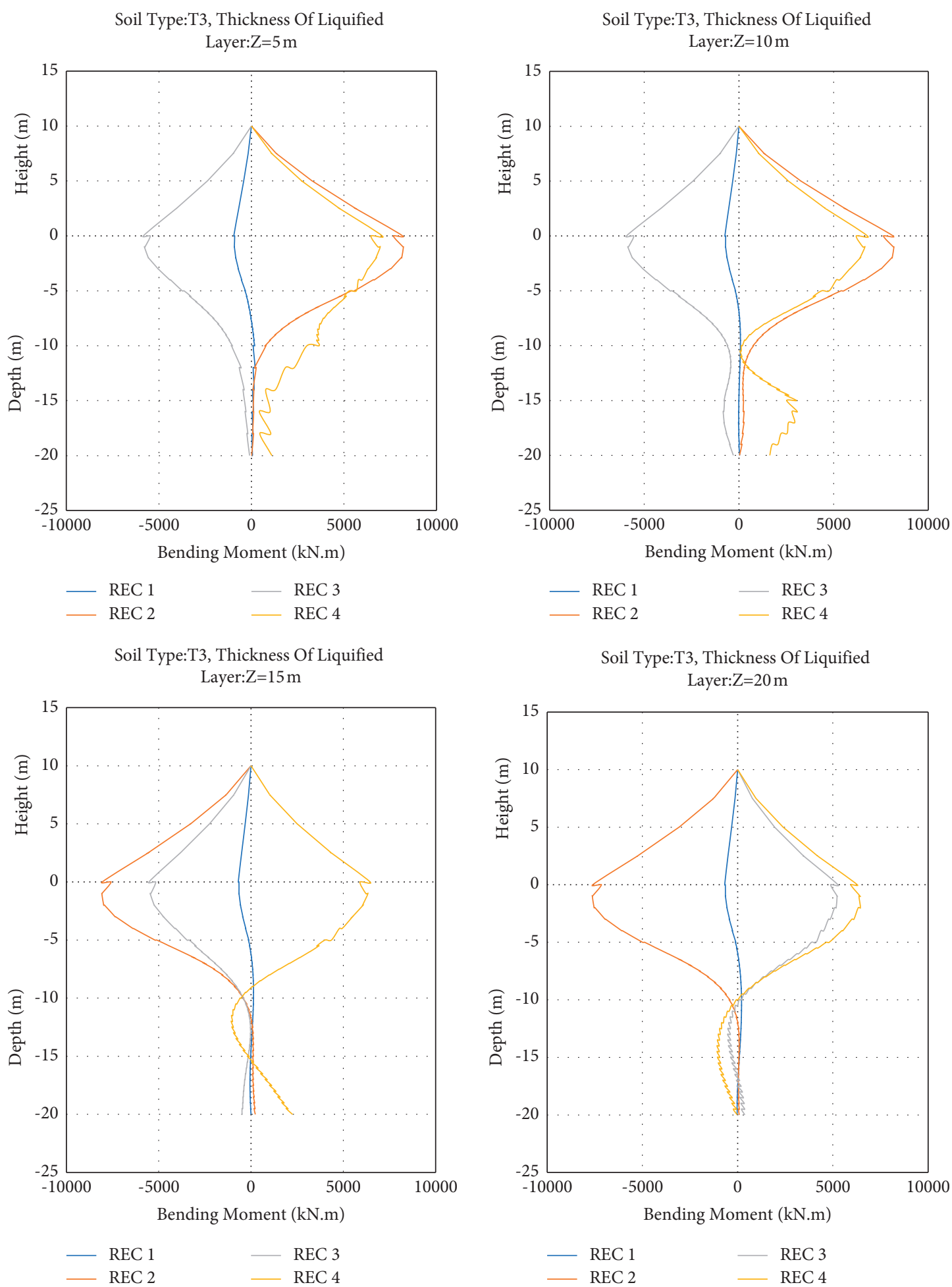

Figure 18: Pile-column bending moment in type T3 soil with different liquefaction layer thicknesses and earthquake records.

(a) As the soil density increased, lateral displacement at the top of the pile column decreased. Hence, the maximum lateral displacement of the top for type $\mathrm{T} 1$ soil under earthquake record 4 in the liquefying layer with a thickness of $10 \mathrm{~m}$ was about $55 \mathrm{~cm}$, and for type T4 soil, it was about $12 \mathrm{~cm}$. (b) Increasing the power of the wind turbine increased the lateral displacement of the top of the pile column. By changing the turbine power from $2 \mathrm{~kW}$ to $5 \mathrm{~kW}$, the rate of increase in the lateral displacement of the pile-column tip in T1-type soil was about 10\%; in T2-type soil, it was about 

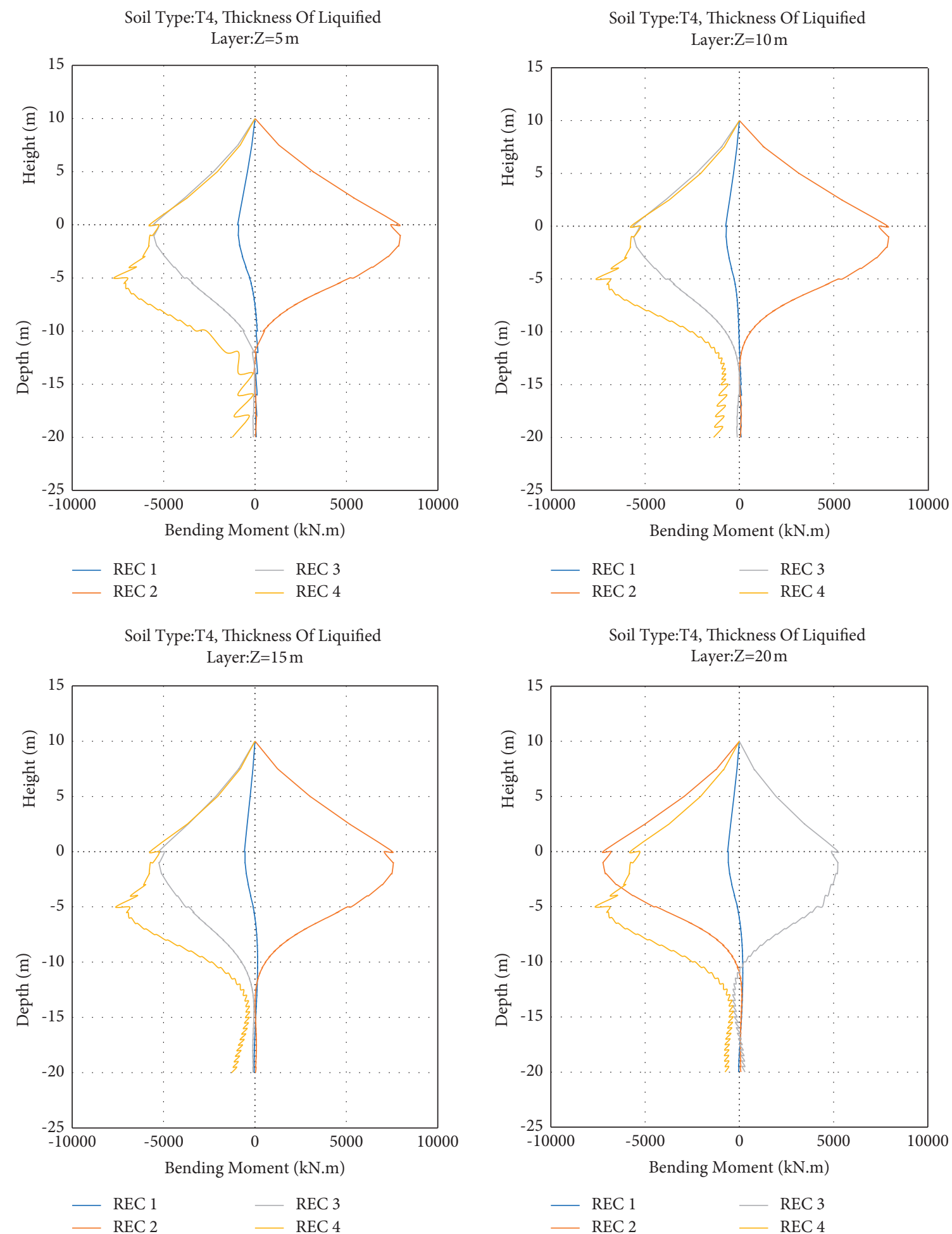

FIGURE 19: Pile-column flexural moment in type T4 soil with different liquefaction layer thicknesses and earthquake records. 
Soil type: T1, Turbine Power:2 kw

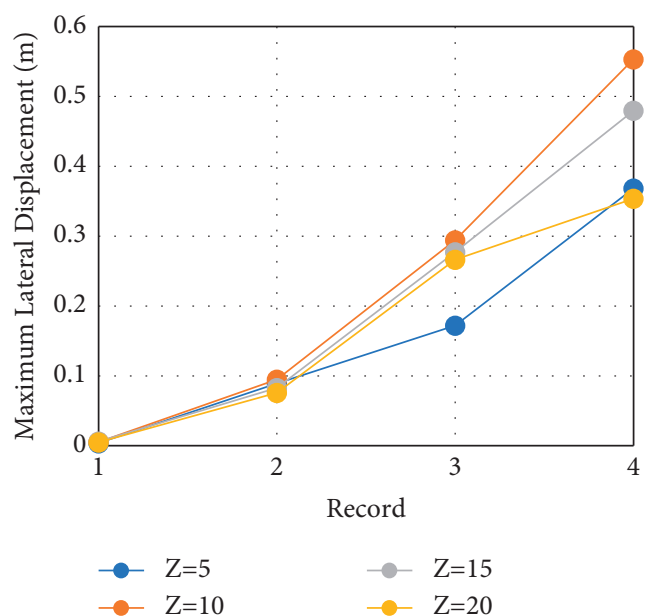

Soil type: T3, Turbine Power:2kw

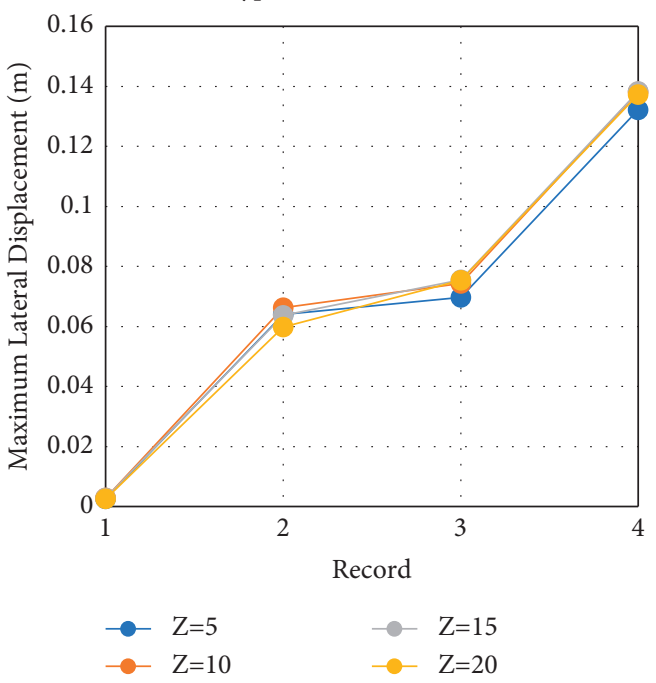

Soil type: T2, Turbine Power:2kw

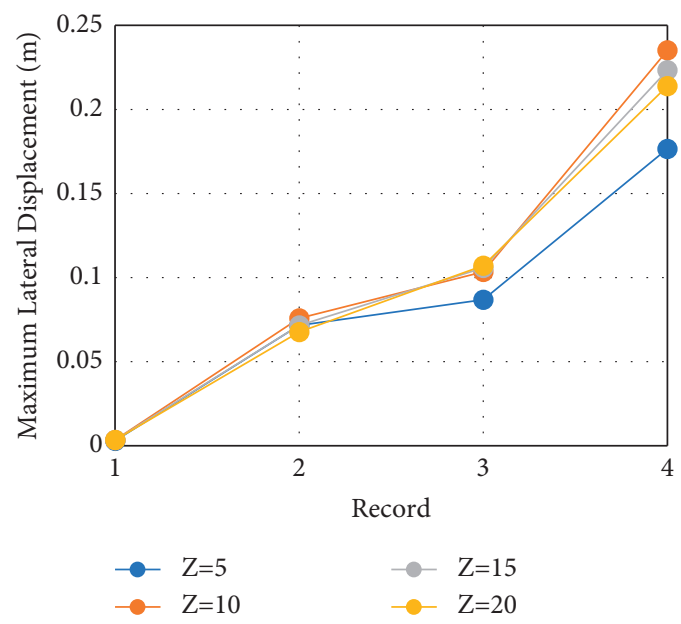

Soil type: T4, Turbine Power: $2 \mathrm{kw}$

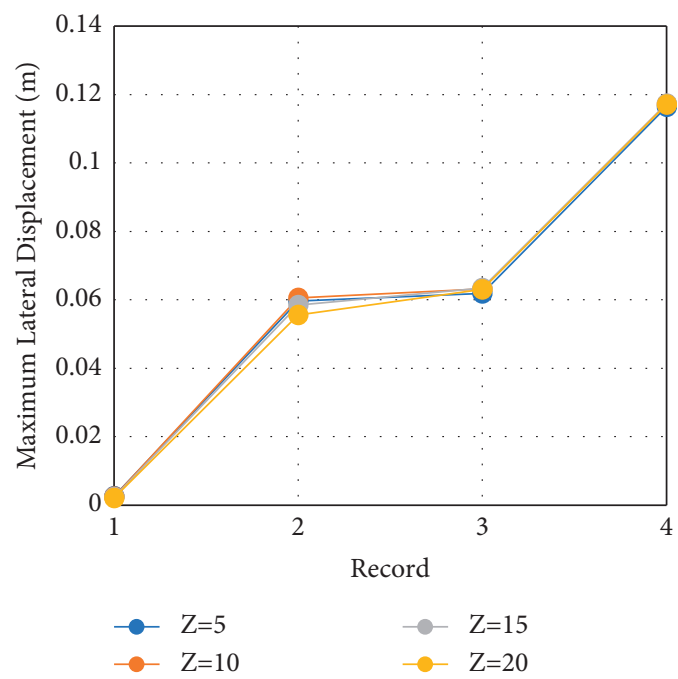

FIGURE 20: Absolute maximum lateral displacement at top of pile column (wind turbine power: $2 \mathrm{~kW}$ ).

$15 \%$; in T3-type soil, it was about $28 \%$; and in T4type soil, it was about $33 \%$.

5.4. Effect of Turbine Weight on Bending Moment Values. The 128 models were analyzed using OpenSees PL to examine the changes in the flexural moment envelope of the pile column. Then, the maximum values for the flexural moment of the pile column were obtained and its envelope curve was drawn. Figure 22 shows the envelope diagrams for the $2 \mathrm{~kW}$ turbine, and Figure 23 shows the envelope diagrams for the $5 \mathrm{~kW}$ turbine. Comparison of the figures shows that the following results:

(a) As the acceleration of the earthquake increased, as long as liquefaction did not occur and the shape or mode of deformation of the pile-column was rotation-displacement, the flexural anchor of the pilecolumn increased. When the acceleration and liquefaction increased, and the pile started to float in response to transfer motion, the difference between the pile-column displacements was not large and the 
Soil type: T1, Turbine Power:5kw
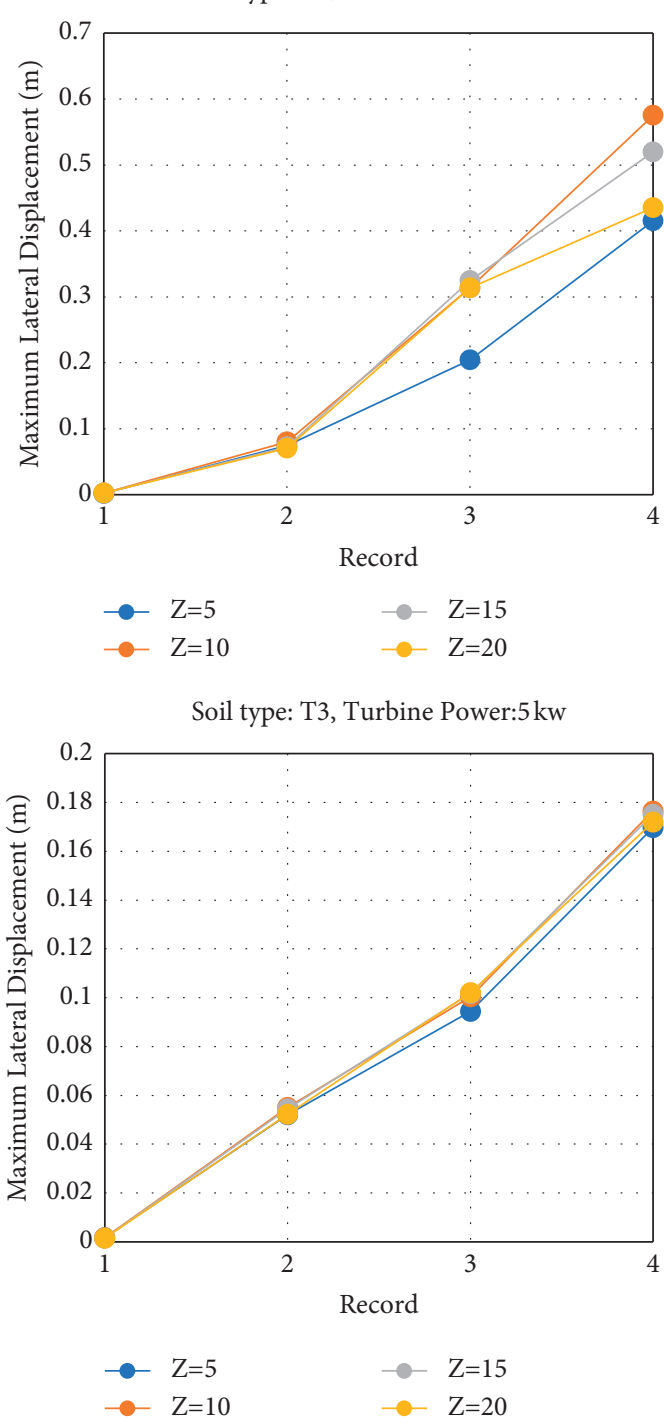
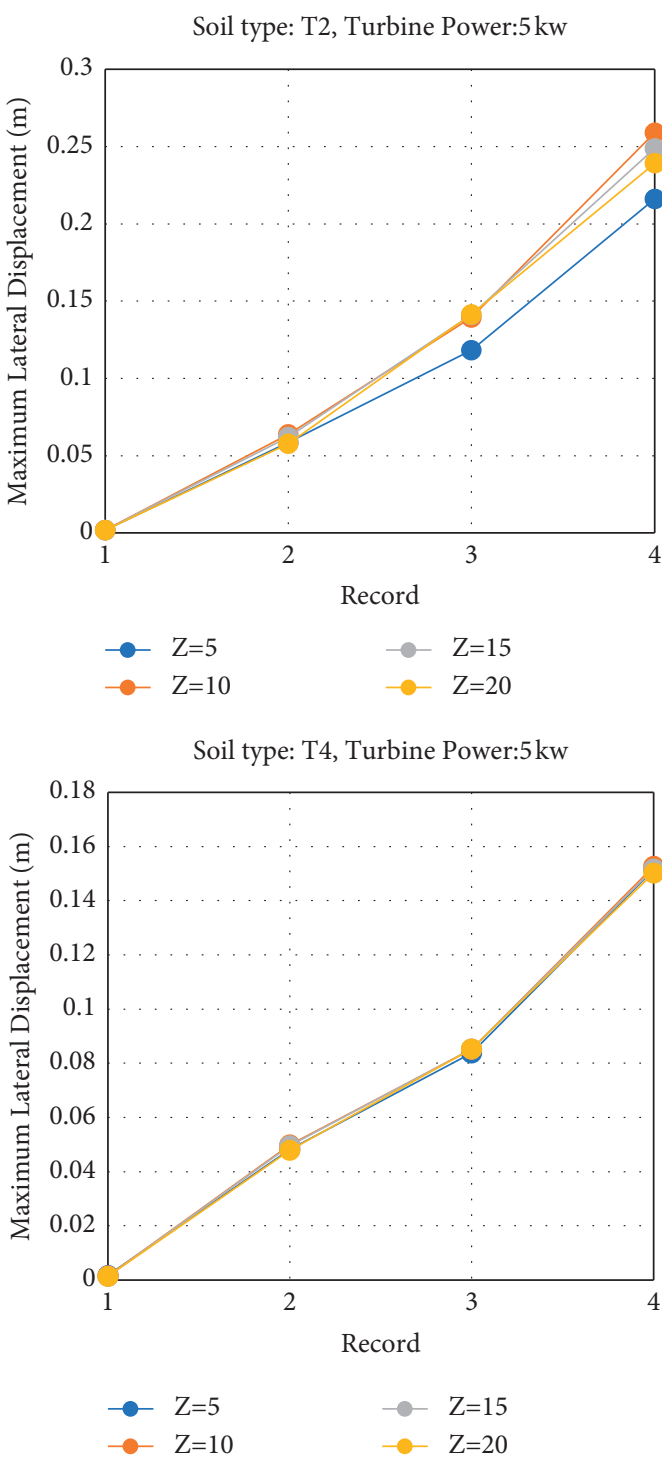

FIGURE 21: Absolute maximum lateral displacement at the top of pile column (wind turbine power: $5 \mathrm{~kW}$ ).

values of the pile-column flexural moment decreased. As the acceleration increased and liquefaction continued, the pile continued to float due to transitional motion and the difference between the pile-column displacements was large; thus, the bending moment increased further.

(b) Increasing the power of the wind turbine increased the bending moment of the pile column. The rate of increase in a displacement increased as the soil density increased. By changing the turbine power from $2 \mathrm{~kW}$ to $5 \mathrm{~kW}$, the rate of increase in the pilecolumn flexural moment in T1-type soil was about $10 \%$, in T2-type soil was about $11 \%$, in T3-type soil was about $23 \%$, and in T4-type soil was about $37 \%$.

\section{Summary and Conclusion}

This research focused on the geostructural performance of monopile wind turbines in the four types of liquefied sand with thicknesses of 5, 10,15, and $20 \mathrm{~m}$. The liquefied sand was 

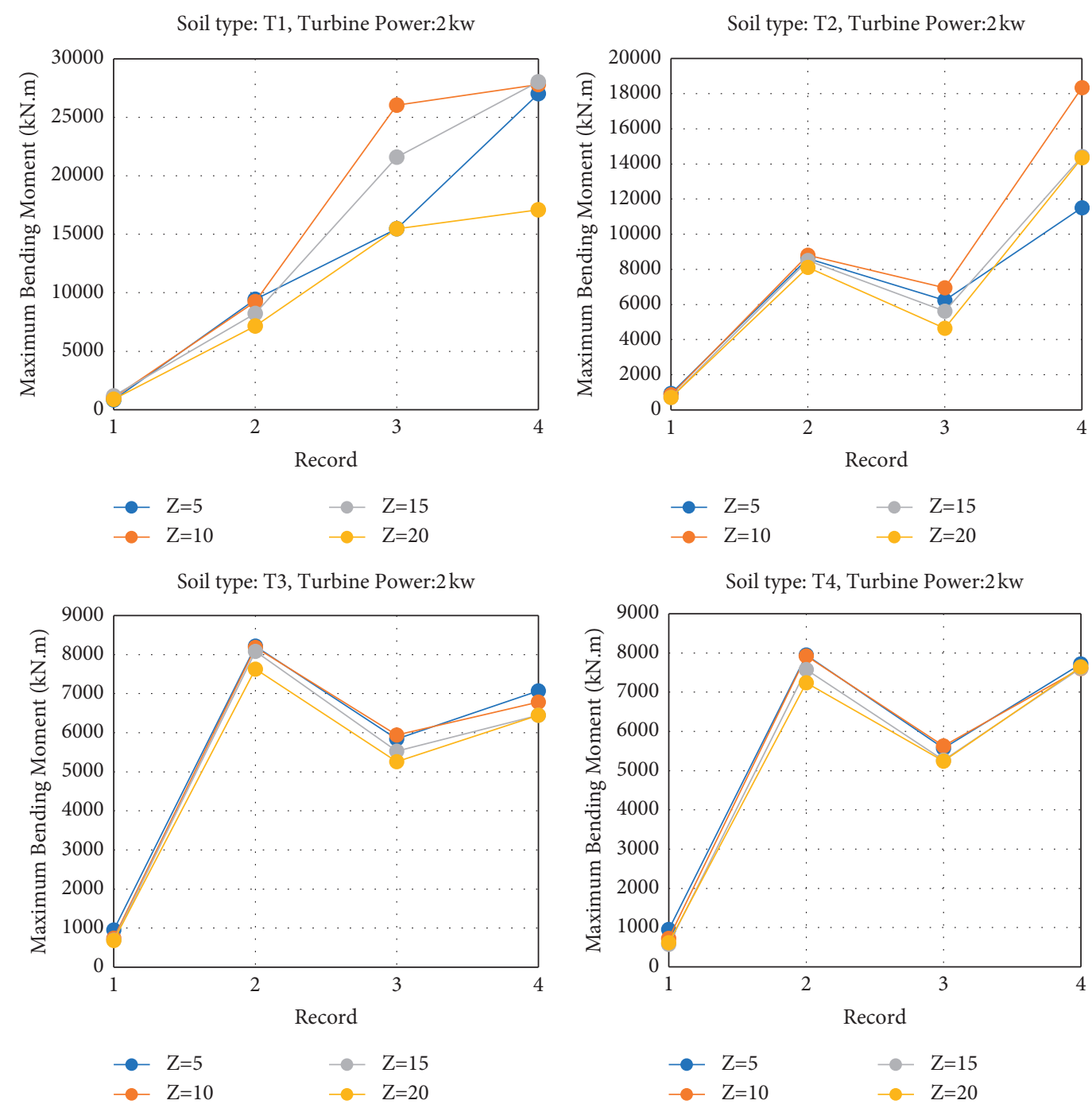

FIgURE 22: Absolute maximum bending moment of pile-column (wind turbine power: $2 \mathrm{~kW}$ ).

under a clay layer having a thickness of $5 \mathrm{~m}$ under loads of 2 and $5 \mathrm{~kW}$ using four far-field records. OpenSees PL was used for analysis and demonstrated that with a decrease in the density of the liquefied sand or if the thickness of the liquefied layer was greater than $10 \mathrm{~m}$, when the earthquake acceleration increased to beyond $0.4 \mathrm{~g}$, the pile floated like liquefied soil and lost its vertical bearing capacity.

Using a constant PGA, four liquefied layer depths and the four types of sandy soil produced 16 different models. The analysis derived the maximum values for all 13 parameters examined.
In the presence of a liquefaction-prone layer, liquefaction occurred as the earthquake acceleration increased. When the fixed point of the pile moved from near the ground surface to the end of the liquefaction layer, the maximum bending moment occurred at the end of the liquefying layer.

During liquefaction, when there was a liquefaction-prone layer, an increase in earthquake acceleration and the thickness of the liquefaction layer changed the shape or mode of lateral displacement from rotation-displacement to tilt. This caused the soil to float and the pile-column to change. This change in 

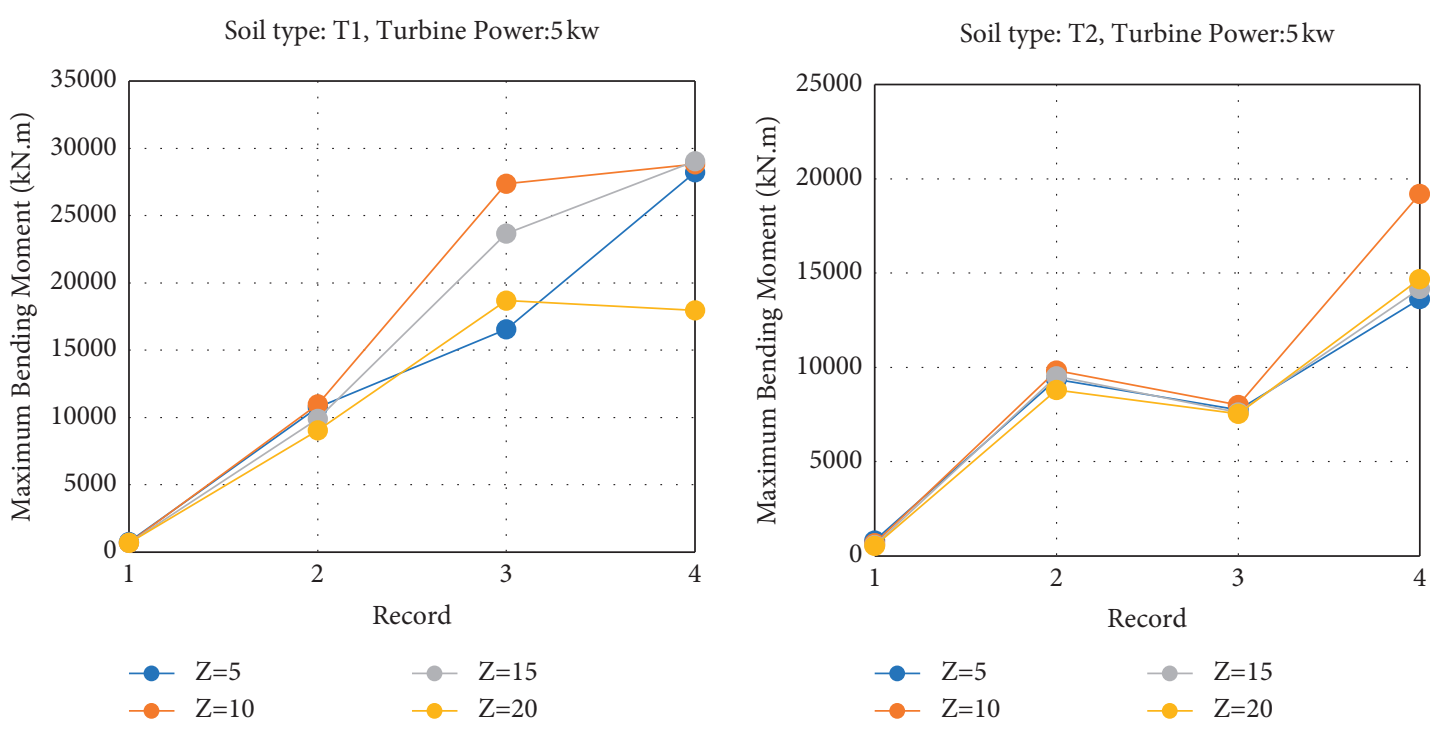

Soil type: T3, Turbine Power:5kw
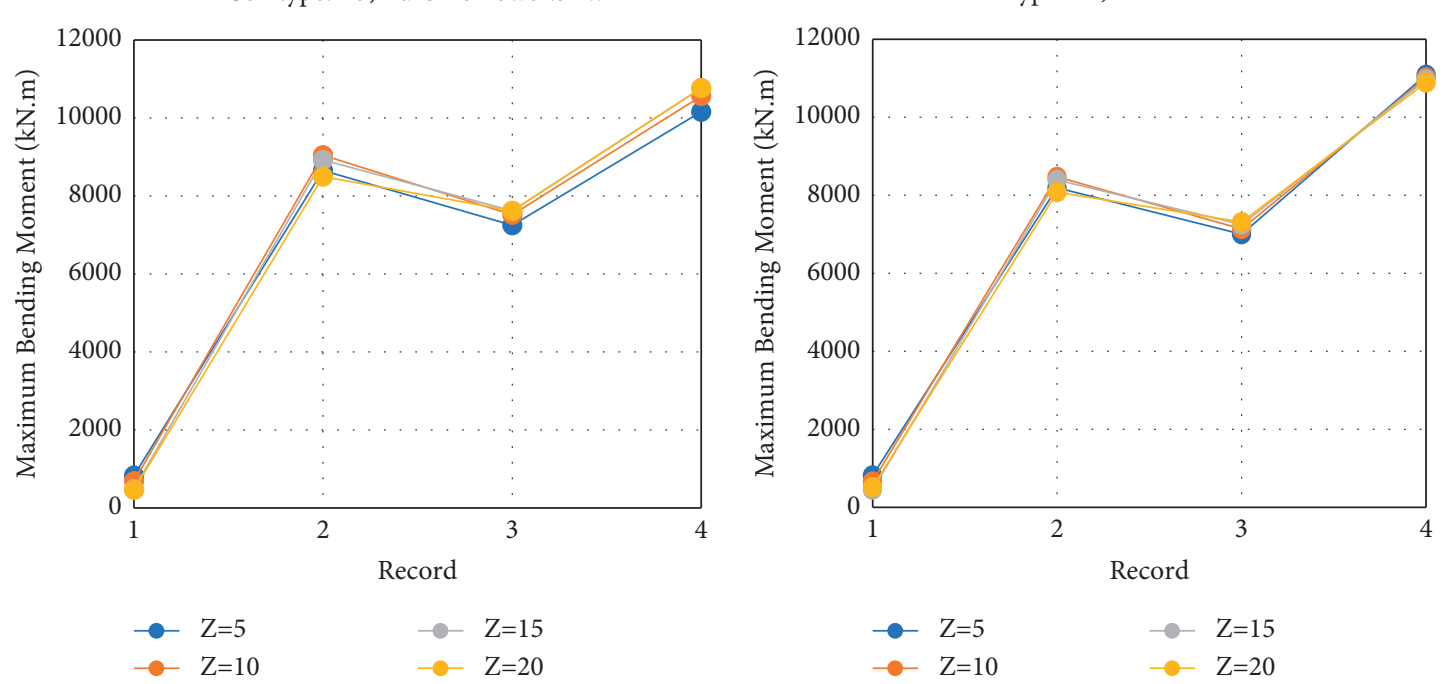

FIgURE 23: Absolute maximum bending moment of pile-column (wind turbine power: $5 \mathrm{~kW}$ ).

the pile-column deformation behavior resulted in a reduction in the lateral displacement of the pile-column top as well as a decrease in its bending moment.

It should be noted that a 2.5 -fold increase in the wind turbine weight from $2 \mathrm{~kW}$ to $5 \mathrm{~kW}$ in soils having different densities and for different thicknesses of the liquefied layer caused changes of $10 \%$ to $33 \%$ in the amount of lateral displacement of the pile tip and of $10 \%$ to $37.5 \%$ in the bending moment.

\section{Conflicts of Interest}

The authors declare that they have no conflicts of interest.

\section{References}

[1] J. Li, X. Wang, Y. Guo, X. Yu, and B. Yu, "The loading behavior of innovative monopile foundations for offshore wind turbine based on centrifuge experiments," Renewable Energy, vol. 152, pp. 1109-1120, 2020.
[2] R. D. Risi, S. Bhattacharya, and K. Goda, "Seismic performance assessment of monopile-supported offshore wind turbines using unscaled natural earthquake records," Soil Dynamics and Earthquake Engineering, vol. 109, pp. 154-172, 2018.

[3] G. Council, Global Wind Report 2016-annual Market Update, Global Wind Energy Council, Brussels, Belgium, 2016.

[4] S. Bhattacharya, N. George, L. Arany, and N. Nikitas, "Soilstructure interactions (SSI) for offshore wind turbines," IET Reference, vol. 1, 2017.

[5] E. Kausel, "Early history of soil-structure interaction," Soil Dynamics and Earthquake Engineering, vol. 30, no. 9, pp. 822-832, 2010.

[6] S. Bisoi and S. Haldar, "Design of monopile supported offshore wind turbine in clay considering dynamic soil-structure-interaction," Soil Dynamics and Earthquake Engineering, vol. 73, pp. 103-117, 2015.

[7] S. Austin and S. Jerath, "Effect of soil-foundation-structure interaction on the seismic response of wind turbines," Ain Shams Engineering Journal, vol. 8, no. 3, pp. 323-331, 2017. 
[8] R. A. Kjørlaug and A. M. Kaynia, "Vertical earthquake response of megawatt-sized wind turbine with soil-structure interaction effects," Earthquake Engineering \& Structural Dynamics, vol. 44, pp. 2341-2358, 2015.

[9] B. Yeter, Y. Garbatov, and C. S. Guedes, "Uncertainty analysis of soil-pile interactions of monopile offshore wind turbine support structures," Applied Ocean Research, vol. 82, pp. 74-88, 2019.

[10] X. Li, X. Zeng, and X. Wang, "Feasibility study of monopilefriction wheel-bucket hybrid foundation for offshore wind turbine," Ocean Engineering, vol. 204, Article ID 107276, 2020.

[11] M. Arshad and B. C. O'Kelly, "Analysis and design of monopile foundations for offshore wind-turbine structures," Marine Georesources \& Geotechnology, vol. 34, no. 6, pp. 503-525, 2016.

[12] Z. Luo, Z. Wu, and L. Fu, "Simplified procedure for laterally loaded drilled shafts in spatially random clays," Marine Georesources \& Geotechnology, vol. 38, pp. 1-14, 2019.

[13] S. S. Nimbalkar, P. Punetha, S. Basack, and M. Mirzababaei, "Piles subjected to torsional cyclic load: numerical analysis," Frontiers in Built Environment, vol. 5, 2019.

[14] M. Arshad and B. O’Kelly, "Global status of wind power generation: theory, practice, and challenges," International Journal of Green Energy, vol. 16, no. 14, pp. 1073-1090, 2019.

[15] C. Yang, R. Wang, and J. Zhang, "A simplified method for analyzing the fundamental frequency of monopile supported offshore wind turbine system design," Earthquake Engineering and Engineering Vibration, vol. 17, no. 4, pp. 893-901, 2018.

[16] S. Roach, S. M. Park, E. Gaertner, J. Manwell, and M. Lackner, "Application of the new IEC international design standard for offshore wind turbines to a reference site in the Massachusetts offshore wind energy area," Journal of Physics: Conference Series, vol. 1452, Article ID 012038, 2020.

[17] B. W. Byrne, G. T. Houlsby, and J. B. Harvey, "PISA design model for monopiles for offshore wind turbines: application to a stiff glacial clay till," Géotechnique, vol. 70, pp. 1-18, 2020.

[18] E. Kementzetzidis, S. Corciulo, W. G. Versteijlen, and F. Pisanò, "Geotechnical aspects of offshore wind turbine dynamics from 3D non-linear soil-structure simulations," Soil Dynamics and Earthquake Engineering, vol. 120, pp. 181-199, 2019.

[19] A. M. Page, K. S. Skau, H. P. Jostad, and G. R. Eiksund, “A new foundation model for integrated analyses of monopile-based offshore wind turbines," Energy Procedia, vol. 137, pp. 100107, 2017.

[20] Api, API-RP 2A: Recommended Practice for Planning, Designing and Constructing Fixed Offshore Platforms-Working Stress Design ForewordAmerican Petroleum Institute, Washington (DC), USA, 2014.

[21] P. K. Esfeh and A. M. Kaynia, "Earthquake response of monopiles and caissons for Offshore Wind Turbines founded in liquefiable soil," Soil Dynamics and Earthquake Engineering, vol. 136, Article ID 106213, 2020.

[22] P. Wang, M. Zhao, X. Du, J. Liu, and C. Xu, "Wind, wave and earthquake responses of offshore wind turbine on monopile foundation in clay," Soil Dynamics and Earthquake Engineering, vol. 113, pp. 47-57, 2018.

[23] J. Liu, X. Bao, D. Wang, H. Tan, and S. Li, "The internal substructure method for seismic wave input in 3D dynamic soil-structure interaction analysis," Soil Dynamics and Earthquake Engineering, vol. 127, Article ID 105847, 2019.

[24] A. Khosravifar, Analysis and Design for Inelastic Structural Response of Extended Pile Shaft Foundation in Laterally
Spreading Ground during Earthquakes, University of California, Davis, California, USA, 2012a.

[25] M. Zarrin and B Asgarian, "Reducing error of probabilistic seismic demand analysis of jacket type offshore platforms subjected to pulse-like near fault ground motions," Journal of Marine Engineering, vol. 8, pp. 33-49, 2013.

[26] J. Zhang, T. C. Hutchinson, and X. Ling, "Demand evaluation of pile shafts embedded in liquefiable soils," in Contemporary Topics in In Situ Testing, Analysis, and Reliability of Foundations, pp. 222-229, ASCE, Reston, VA, USA, 2009.

[27] F. McKenna and G. L. Fenves, "OpenSees manual, PEER center," 2001, https://opensees.berkeley.edu/.

[28] S. Mazzoni, F. McKenna, M. H. Scott, and G. L. Fenves, "OpenSees command language manual," Pacific Earthquake Engineering Research (PEER) Center, p. 264, University of California, Berkeley, Berkeley, California, USA, 2006.

[29] J. H. Prevost, "A simple plasticity theory for frictional cohesionless soils," International Journal of Soil Dynamics and Earthquake Engineering, vol. 4, no. 1, pp. 9-17, 1985.

[30] A. Elgamal, Z. Yang, and E. Parra, "Computational modeling of cyclic mobility and post-liquefaction site response," Soil Dynamics and Earthquake Engineering, vol. 22, no. 4, pp. 259-271, 2002.

[31] A. Elgamal, Z. Yang, E. Parra, and A. Ragheb, "Modeling of cyclic mobility in saturated cohesionless soils," International Journal of Plasticity, vol. 19, no. 6, pp. 883-905, 2003.

[32] M. A. Biot, "Mechanics of deformation and acoustic propagation in porous media," Journal of Applied Physics, vol. 33, no. 4, pp. 1482-1498, 1962.

[33] O. C. Zienkiewicz and T. Shiomi, "Dynamic behaviour of saturated porous media; the generalized Biot formulation and its numerical solution," International Journal for Numerical and Analytical Methods in Geomechanics, vol. 8, no. 1, pp. 71-96, 1984.

[34] O. C. Zienkiewicz, A. H. C. Chan, M. Pastor, B. A. Schrefler, T. Shiomi, and G. Maier, "Computational geomechanics: with special reference to earthquake engineering," Meccanica, vol. 35, p. 76, 2000.

[35] A. W. Elgamal, J. Lu, and D. Forcellini, "Mitigation of liquefaction-induced lateral deformation in a sloping stratum: three-dimensional numerical simulation," Journal of Geotechnical and Geoenvironmental Engineering, vol. 135, 2009.

[36] A. Khosravifar, R. W. Boulanger, and S. K. Kunnath, "Effects of liquefaction on inelastic demands on extended pile shafts," Earthquake Spectra, vol. 30, no. 4, pp. 1749-1773, 2014.

[37] A. Khosravifar and R. W. Boulanger, "Inelastic response of extended pile shafts in laterally spreading ground during earthquakes (student paper competition 2010)," DFI Journal: The Journal of the Deep Foundations Institute, vol. 4, no. 2, pp. 41-53, 2010.

[38] M. M. Chiaramonte, P. Arduino, D. E. Lehman, and C. W. Roeder, "Seismic analyses of conventional and improved marginal wharves," Earthquake Engineering \& Structural Dynamics, vol. 42, no. 10, pp. 1435-1450, 2013.

[39] D. W. Wilson, "California, transportation department of, davis university of California, and modeling center for geotechnical," Soil-pile-superstructure Interaction in Liquefying Sand and Soft clay, Center for Geotechnical Modeling, Dept. of Civil and Environmental Engineering, University of California, Davis, California, US, 1998.

[40] D. W. Wilson, R. W. Boulanger, and B. L. Kutter, "Observed seismic lateral resistance of liquefying sand," Journal of Geotechnical and Geoenvironmental Engineering, vol. 126, no. 10, pp. 898-906, 2000. 